\title{
Induction of senescence upon loss of the Ash2l core subunit of H3K4 methyltransferase complexes
}

Agnieszka Bochyńska ${ }^{1,5}$, Alexander T. Stenzel ${ }^{1,5}$, Roksaneh Sayadi Boroujeni ${ }^{1,5}$, Chao-Chung Kuo ${ }^{2,3}$, Mirna Barsoum ${ }^{1}$, Weili Liang ${ }^{1,4}$, Philip Bussmann ${ }^{1}$, Ivan G. Costa ${ }^{2}$, Juliane Lüscher-Firzlaff ${ }^{1}$, and Bernhard Lüscher ${ }^{1}$

${ }^{1}$ Institute of Biochemistry and Molecular Biology, Faculty of Medicine, RWTH Aachen University, Pauwelsstrasse 30, 52057 Aachen, Germany

${ }^{2}$ Institute for Computational Genomics, Faculty of Medicine, RWTH Aachen University, Pauwelsstrasse 30, 52057 Aachen, Germany

${ }^{3}$ Interdisciplinary Center for Clinical Research (IZKF), Faculty of Medicine, RWTH Aachen University, Aachen, Germany

${ }^{4}$ Present Address: Department of Thyroid Surgery, General Surgery, Qilu Hospital of Shandong University, Jinan, Shandong, China

${ }^{5}$ Equal contribution

Correspondence to B.L. (luescher@rwth-aachen.de)

\section{ORCID}

Roksaneh Sayadi Boroujeni: 0000-0002-2481-1663

Chao-Chung Kuo: 0000-0001-8879-4754

Mirna Barsoum: 0000-0003-0838-8137

Ivan G. Costa: 0000-0003-2890-8697

Juliane Lüscher-Firzlaff: 0000-0001-9265-8536

Bernhard Lüscher: 0000-0002-9622-8709

\section{Key words}

Ash2l knockout, cell cycle, chromatin, COMPASS, FoxM1, gene expression, H3K4me1, H3K4me3, histone modification, KMT2, MLL, mouse embryo fibroblast, MEF, promoter, senescence, Set1, trithorax 


\section{ABSTRACT}

Gene expression is controlled in part by post-translational modifications of core histones. Methylation of lysine 4 of histone H3 (H3K4), associated with open chromatin and gene transcription, is catalyzed by type 2 lysine methyltransferase complexes that require WDR5, RBBP5, ASH2L and DPY30 as core subunits. Ash2l is essential during embryogenesis and for maintaining adult tissues. To expand on the mechanistic understanding of Ash2l, we generated mouse embryo fibroblasts (MEFs) with conditional Ash2I alleles. Upon loss of Ash2I, methylation of $\mathrm{H} 3 \mathrm{~K} 4$ and gene expression were downregulated, which correlated with inhibition of proliferation and cell cycle progression. Moreover, we observed induction of senescence concomitant with a set of downregulated signature genes but independent of SASP. Many of the signature genes are FoxM1 responsive. Indeed, exogenous FOXM1 was sufficient to delay senescence. Thus, although the loss of Ash2l in MEFs has broad and complex consequences, a distinct set of downregulated genes promotes senescence. 


\section{INTRODUCTION}

The regulated expression of defined genes is important for the identity and physiology of cells. Transcription of genes is regulated by sequence specific transcription factors and by cofactors that control chromatin accessibility and polymerase activity. The smallest units of chromatin are the nucleosomes, which are composed of 8 core histones, two copies each of $\mathrm{H} 2 \mathrm{~A}, \mathrm{H} 2 \mathrm{~B}, \mathrm{H} 3$ and $\mathrm{H} 4$ or various variants thereof. Several hundred post-translational modifications (PTM) of core histones have been described, which are thought to regulate specific aspects of transcription 1,2,3. Methylation of histone $\mathrm{H} 3$ at lysine 4 has gained attention because its mono- and tri-methylation (H3K4me1/3) is associated with active enhancers and promoters, respectively. This PTM is catalyzed primarily by lysine-specific methyltransferases of the KMT2 family, consisting of MLL1 to 4, and SET1A and B (KMT2A-D, F and G, respectively). These enzymes are part of multi-subunit complexes, referred to as COMPASS (complex of proteins associated with Set1). All six KMT2 family members associate with the WRAD core complex composed of WDR5, RBBP5, ASH2L, and two copies of DPY30, forming functional KMT2 complexes. WRAD is necessary for catalytic activity of KMT2 enzymes. Additional subunits interact specifically with distinct KMT2 complexes, further increasing the diversity and functionality of these methyltransferases $4,5,6,7,8,9$.

The importance of KMT2 complexes is highlighted by many functional studies. All KMT2 complex subunits, which have been knocked-out, are essential in mice ${ }^{7,8}$. This is true for the 6 enzymatic subunits, which are required during defined developmental processes, indicating at least in part distinct functions. Moreover, the two WRAD core complex subunits, Ash2I and Dpy30, are necessary for organismal development and cell proliferation and differentiation in the mouse $10,11,12,13,14$. Of note is also that mutations in the Drosophila melanogaster orthologue Ash2 cause homeotic transformations, similar to mutations in trithorax, the orthologue of MLL1 and MLL2 ${ }^{15}$, 16, 17. Moreover, KMT2 complex subunits are linked to various diseases, including cancer ${ }^{7,18}$. Together, KMT2 complexes/COMPASS contribute to the control of cell proliferation and differentiation and participate in cell fate decisions.

We identified $\mathrm{ASH} 2 \mathrm{~L}$ as an interaction partner of the oncoprotein c-MYC and our findings suggest that $\mathrm{ASH} 2 \mathrm{~L}$ has oncogenic activity ${ }^{19,20}$. In mice, the loss of Ash2l led to disintegration of hepatocytes ${ }^{14}$. In hematopoietic stem and progenitor cells 
(HSPCs), the knockout of Ash2l resulted in an accumulation of cells in a G2/M cell cycle arrest, accompanied with a proliferation and differentiation stop, that resulted in a loss of mature cells ${ }^{13,14}$. We have now addressed the function of Ash2l in mouse embryo fibroblasts (MEFs). Unlike the findings in hepatocytes and HSPCs, Ash2l loss in MEFs resulted in a senescence phenotype once cells ceased to proliferate. Senescence is a heterogenous response of cells to a broad spectrum of triggers, which include replicative exhaustion with telomer erosion, oncogene activation, and DNA damage as well as other forms of stress that result in the upregulation of many genes, including those expressing cyclin-dependent kinase inhibitors ${ }^{21,22}$. Ash2l loss was accompanied by an overall reduction in gene expression. A small set of downregulated genes are linked to senescence that are also repressed in other senescent cells. Many of these genes are controlled by the transcription factor FoxM1. Its exogenous expression was sufficient to delay senescence. Thus, MEF cells respond to Ash2l loss with a senescence program that depends on downregulation of genes associated with the cell cycle, replication and DNA repair, which is in contrast to the typically observed upregulation of genes. 


\section{RESULTS}

\section{Ash2I is required for fibroblast cell proliferation}

We prepared MEF cells from mouse embryos that contained a floxed Ash2/ exon 4 and that express a Cre-ER ${ }^{\mathrm{TM} 2}$ recombinase fusion protein. Primary MEFs (pMEFs), were immortalized using an siRNA expression construct that targets the $p 19^{A R F}$ mRNA (iMEFs) 23, 24. Two pairs of iMEF cells were generated, WT1 and WT2 cells (Ash2/wt/wt:Cre-ER ${ }^{T M 2}$ ) and KO1 and KO2 cells (Ash2/f/ffl:Cre-ER ${ }^{T M 2}$ ), each pair from 2 embryos of the same mother. Upon treatment with 4-hydroxy tamoxifen (HOT), which activates the constitutively expressed recombinase, exon 4 sequences were lost in $\mathrm{KO}$ but not in WT cells (Suppl. Fig. S1A) and exon 4 containing RNA expression decreased strongly (Fig. 1A). This was followed by a decrease of Ash2l in KO2 cells (Fig. 1B) and in KO1 and pMEF cells (Suppl. Fig. S1B and C), albeit slowly due to the long half-life of Ash2I protein ${ }^{20}$. As a result, H3K4 methylation decreased (Fig. $1 \mathrm{C}$ and Suppl. Fig. S1B-D), as expected when one of the core components of KMT2 complexes is lost. Moreover, Rbbp5 containing complexes lost H3K4 methyltransferase activity when isolated from cells without Ash2l (Fig. 1D). Rbbp5, a direct interaction partner of Ash2I, was reduced at late time points, while Wdr5 was not (Fig. 1 and Suppl. Fig. S1). The loss of Ash2l did not affect RNA expression of the core components $W d r 5, R b b p 5$, and Dpy30, and the different catalytic subunits (Suppl. Fig. S1E). Thus, loss of Ash2l prevented H3K4 methylation, consistent with previous studies addressing the role of KMT2 complexes ${ }^{7,8}$.

Ash2l loss inhibited MEF proliferation beginning between day 3 and 5 upon HOT treatment and ceased by day 6 (Fig. 1E and Suppl. Fig. S2A). This correlated with the decrease in Ash2l and in H3K4me3 and me1. Unlike in HSPCs, we did not observe an accumulation in the G2/M phase, rather the distribution of the cells in the different cell cycle phases remained largely unaffected with a small increase in $S$ phase at day 7 (Fig. 1F and Suppl. Fig. S2B and C). This suggested that the cells were unable to transit the cell cycle upon downregulation of Ash2l. To address whether the cells were stalled in the cell cycle, proliferating iMEFs were treated for 18 hours with nocodazole, which arrests cells in early mitosis ${ }^{25}$. In the absence of HOT, both WT2 and KO2 cells accumulated in G2/M, concomitant with a decrease in G0/G1 cells (Fig. 1G). Similarly, an increase in G2/M phase, albeit smaller, was seen in HOT treated WT2 cells. WT cells proliferated slower upon HOT treatment (Fig. 1E and Suppl. Fig. S2A), explaining 
the reduced G2/M accumulation. In the absence of Ash2I, the accumulation of KO2 cells in G2/M was minimal (Fig. 1G), indicating that these cells were unable to transit through the cell cycle.

We also considered that the loss of Ash2l induced apoptosis, thereby influencing overall proliferation. We did not notice an increase in sub-G0/G1 cells in flow cytometry (Suppl. Fig. S2C). Consistent with this observation, staining cells for annexin $\mathrm{V}$ and with propidium iodide $(\mathrm{PI})$ did not reveal significant changes, neither in early (annexin V positive) nor late apoptotic cells (both annexin V and PI positive) (Suppl. Fig. S2D and $\mathrm{E})$. Thus, cell death is unlikely to contribute significantly to the reduced cell proliferation.

\section{Loss of Ash2I promotes senescence}

We noticed that the cells became larger upon loss of Ash2I, an attribute of senescent cells (Fig. 2A). Indeed, many cells became SA- $\beta$-galactosidase (SA- $\beta$-gal) positive (Fig. 2A und $B$ ), a frequently used marker for senescence ${ }^{22}$. This phenotype was further assessed by applying senolytic drugs. These have been described to selectively kill senescent cells ${ }^{26}$. For example, the combination of Dasatinib and Quercetin eliminated senescent MEFs ${ }^{27}$. We observed a reduction of more than $50 \%$ of SA- $\beta$-gal positive cells with $250 \mathrm{nM}$ Dasatinib/15 $\mu \mathrm{M}$ Quercetin and a trend to less senescent cells with $25 \mathrm{nM}$ Dasatinib/15 $\mu \mathrm{M}$ Quercetin (Fig. 2C), while $10 \mu \mathrm{M}$ Dasatinib/15 $\mu \mathrm{M}$ Quercetin, the originally described dose for MEFs ${ }^{27}$, efficiently killed all our cells. Moreover, it was noted that the knockdown of phosphoinositide 3 kinase delta $(\mathrm{PI} 3 \mathrm{~K} \delta)$ resulted in a senolytic effect ${ }^{28}$. Inhibiting PI3 kinases with Wortmannin or compound 15 e reduced the number of senescent cells (Fig. 2C) ${ }^{29,30}$. One of the signaling pathways that is activated during senescence involves p38MAPK, a stress response kinase ${ }^{31}$. Indeed, the loss of Ash2l resulted in activating phosphorylation of p38MAPK (Fig. 2D). Thus, the loss of Ash2l in MEF cells promotes senescence.

\section{Downregulation of gene expression upon loss of Ash2l}

A hallmark of senescent cells is the secretion of signaling and extracellular matrix modulating molecules, at least in part due to an altered gene expression program, referred to as senescence-associated secretory phenotype (SASP) $22,32,33$. Because KMT2 complexes are associated with altered gene transcription, we performed RNA- 
seq experiments to evaluate changes in gene expression, which might account for the senescence phenotype, upon Ash2I loss five days after HOT addition (Suppl. Table S1). In view of the strong correlation of H3K4me1 and me3 with active enhancer and promoters, respectively, we expected broad effects on gene expression and cellular RNA content. To compensate for this, we used ERCC (External RNA Controls Consortium) spike-in RNA. Roughly $75 \%$ of all genes (37205) showed reduced expression $\left(\log _{2} \mathrm{FC}<0\right)$ in the HOT treated $\mathrm{KO} 1$ and $\mathrm{KO} 2$ cells (Fig. 3A and $\mathrm{B}$ ). We observed 1118 and 1600 significantly downregulated genes in KO1 and KO2 cells, respectively (Fig. 3A and $\mathrm{C}$ ). Also, a small number of genes were up-regulated (176 and 207 in KO1 and KO2 cells, respectively) (Fig. 3A and C). Of note, all the apparently upregulated genes had very low basal expression (Suppl. Table S1).

Altered gene expression was verified in independent RT-qPCR experiments. Ash2I exon 4 expression was strongly decreased as expected (Fig. 3A and D). The expression of $\beta$-glucuronidase (Gusb) was only slightly downregulated, consistent with the trend to decreased expression of many genes, and served as control (Fig. 3D). RNA-seq revealed that Flywch2, Tcfl5 and Cdh3 were downregulated, the former two being in the top group. Cdh17 and Olfr456 were up-regulated while the expression of Hsp90b1 showed little change (Suppl. Table S1). The differential expression of these genes was reproduced in the RT-qPCR experiments (Fig. 3D). Thus, the loss of Ash2I resulted in broadly deregulated gene expression.

We employed gene ontology (GO) analyses to evaluate whether the deregulated genes would allow to make predictions about the cellular processes that might be affected upon Ash2l loss, particularly considering a link to senescence. A large number of terms were observed for downregulated genes (Suppl. Fig. S3A), When upregulated genes were analyzed, only 4 GO terms were statistically significant (Suppl. Fig. S3B). The terms were very broad, but included some related to cell cycle and proliferation. Nevertheless, terms that would suggest a direct link to senescence were not observed in either group.

\section{Gene repression is associated with senescence}

One of the key events is the induction of SASP that arguably occurs in all senescent cells ${ }^{22}$. Because SASP is primarily based on gene induction, it is unlikely that this can 
be observed in the Ash2l KO cells as the major response is gene repression (Fig. 3). Therefore, we compared our downregulated genes with those of two studies ${ }^{34,35}$. In one senescence was induced in three primary human cell populations, i.e. umbilical vein endothelial cells, fetal lung fibroblasts, and mesenchymal stromal cells, by replicative exhaustion ${ }^{35}$. Gene expression was measured when roughly $65 \%$ senescent cells had accumulated as determined by SA- $\beta$-gal staining. Of the several hundred downregulated genes in each cell population, 206 were in common between the 3 cell populations ${ }^{35}$. We found that 37 and 87 homologous genes were significantly downregulated in $\mathrm{KO} 1$ and $\mathrm{KO} 2$ cells, respectively, despite comparing human and mouse expression patterns. Thirty-three of these genes were downregulated in both KO iMEF populations (Fig. $4 \mathrm{~A}$ and $\mathrm{B}, \mathrm{B}+\mathrm{M}$ genes). In the second study, replicative senescence was analyzed in human diploid fibroblasts ${ }^{34}$. Downregulated genes were enriched for pathways associated with proliferation and replication. We observed an overlap of 72 genes with our dataset (Fig. 4A and B, A+M genes). Moreover, the genes in the $\mathrm{M}$ group are also downregulated in other studies of cellular senescence ${ }^{36,37 .}$ Importantly, GO pathway analyses of these genes ( $A, B$ and $M$ ) revealed terms associated with cellular senescence (Fig. 4C, e.g. cellular senescence, p53 signaling pathway). Consistent with inhibition of proliferation and cell cycle progression were additional terms (Fig. 4C, e.g. Faconi anemia pathway, p53 signaling pathway, FoxO signaling pathway) and the repression of many genes associated with the cell cycle and replication (Suppl. Table S2). Also the terms relating to virus infection are consistent with a proliferation stop as cellular response and senescence (Fig. 4C) ${ }^{38}$. Together, these changes in gene expression render further support for induction of senescence upon Ash2I loss.

To obtain information about the dynamics of events, e.g. whether a transient SASP response might occur, we performed time course experiments. The first SA- $\beta$-gal positive cells appeared at day 4 (Fig. 5A), concomitant with inhibition of cell proliferation (Fig. $1 \mathrm{E}$ and $\mathrm{S} 2 \mathrm{~A}$ ). The loss of Ash2l and the decrease in H3K4 methylation may affect chromatin and provoke transcription-replication conflicts ${ }^{39}$, which may result in DNA damage that is known to contribute to induction of senescence ${ }^{40}$. Therefore, we measured $\gamma-\mathrm{H} 2 \mathrm{AX}$, the phosphorylated form of histone H2AX, a marker for double strand DNA breaks ${ }^{41,42}$. Occasionally we observed Ash2I negative cells that stained positive for $\gamma-\mathrm{H} 2 \mathrm{AX}$ at day 5 (Suppl. Fig. S4A). However, no 
broad induction of $\gamma-\mathrm{H} 2 \mathrm{AX}$ in response to Ash2l loss was observed prior to significant senescence induction at days 5 and 7 (Suppl. Fig. S4A).

Because SASP is a prominent feature of senescent cells, we considered that genes expressing SASP factors might be induced transiently, prior to the appearance of SA$\beta$-gal positive cells. This might occur prior to inhibition of cell proliferation, which we may have missed in our RNA-seq experiments. Therefore, we measured RNA expression over 7 days upon HOT treatment. For control, two downregulated, Flywch2 and $\mathrm{Cdh} 3$, and two up-regulated genes, Cdh17 and Olfr456, were measured (Fig. 5B). Flywch2 and Cdh3 were strongly repressed by day 3 while induction of RNA expression was a late event. This supports the notion that upregulation of genes was most likely an indirect consequence of Ash2I loss. We analyzed three SASP genes, IL6, IL7 and CCl2, that show basal expression in MEF cells and which are typically upregulated in senescent cells ${ }^{22}$. All three were initially downregulated. At later time points, parallel to the appearance of SA- $\beta$-gal positive cells, IL6 and IL7 expression was enhanced (Fig. 5B). At present it is unclear how the mRNAs of these genes are upregulated. Additionally, we analyzed two genes, Gstm4 and CntIn, that were identified as downregulated core senescence signature genes in three different cell types, including human foreskin fibroblasts ${ }^{43}$. Both were also repressed in our iMEF cells (Fig. 5B).

\section{The transcription factor FOXM1 delays senescence induced by Ash2I loss}

When the $\mathrm{M}$ genes were analyzed, it was obvious that many fulfill functions in the regulation of the cell cycle, in particular the metaphase - anaphase transition, and in DNA repair and genomic stability, consistent with the GO analysis (Fig. 4C). Many of the genes in the M group are regulated by the transcription factor FoxM1 (e.g. 44, 45, 46, 47,48 ), some of which antagonize senescence (e.g. ${ }^{49,50,51}$ ). Moreover, FoxM1 itself is promoting cell cycle progression, having functional relevance both at the G1-S and the G2-M transitions (e.g. 52, 53, 54, 55, 56). Also, in several cellular systems, the exogenous expression of FoxM1 was sufficient to interfere with induction of senescence (e.g. 57 , 58, 59, 60, 61). High mobility group proteins, including $\mathrm{Hmgb2}$, possess functions in the control of chromatin and its downregulation is an early marker for senescence and aging $35,62,63$. Conversely, the expression of HMGB2 is induced when cells enter the cell cycle from a quiescent state ${ }^{64}$. A role of HMGB2 in senescence is further 
supported by its ability to inhibit the spreading of heterochromatin, which ensures expression of SASP genes ${ }^{65}$. Based on these published findings, we generated iMEF cells in which we introduced inducible expression constructs for FOXM1 and HMGB2, both fused to eYFP, into KO2 cells. Pools of cells were then treated with HOT and the induction of the transgenes induced with doxycycline. The expression of FOXM1 delayed the development of senescent cells, suggesting that FOXM1 and its downstream targets are relevant downregulated genes in the Ash2l model (Fig. 5C). Unlike FOXM1, HMGB2, was not affecting senescence, despite its potential broad role in regulating chromatin and gene transcription. 


\section{Discussion}

We report on the consequences of the loss of Ash2I in MEF cells. Ash2l is necessary for proliferation and cell cycle progression of these cells. The loss of Ash2l does not result in a specific block in the cell cycle but rather cells appear to arrest through all phases. Moreover, we did not observe any cell death, rather the cells developed a flat, senescence-like phenotype. Consistent with senescence, iMEF cells became SA- $\beta$-gal positive. This appears to be the consequence of broad downregulation of gene expression. In particular we noticed a set of downregulated genes that are also apparent in other senescent cells. However, no SASP was observed, which is a hallmark broadly detectable in senescent cells. We noticed that many of the downregulated genes, which are linked to cell cycle progression and stress response, are controlled by the transcription factor FOXM1. This factor is important for cell cycle progression, particularly at the G1-S and G2-M transitions. When Ash2l was deleted in cells that express exogenous FOXM1, senescence was delayed. Together the findings suggest that downregulation of FOXM1 target genes is part of the circuitry that promotes senescence upon Ash2l loss and broad downregulation of gene transcription.

The loss of Ash2l results in depletion of $\mathrm{H} 3 \mathrm{~K} 4$ methylation, consistent with the observations that the WRAD core complex is necessary for KMT2 catalytic activity (Fig. 1) $66,67,68,69,70,71$. H3K4me1 and H3K4me3 correlate well with active enhancers and promoters, respectively $4,8,9$. This is coherent with the observation that most genes are downregulated (Fig. 3). A number of suggestions have been made how H3K4 methylation might affect gene transcription. H3K4me3 provides binding sites for cofactors and thus may contribute to the local organization of chromatin $72,73,74,75,76$. One of the readers that binds to H3K4me3 is TAF3, a subunit of the TFIID complex and thus intimately associated with Pol II loading onto core promoters ${ }^{77}$. TAF3 possesses a PHD finger that recognizes $\mathrm{H} 3 \mathrm{~K} 4 \mathrm{me} 3{ }^{78}$. This interaction is antagonized by asymmetric demethylation of $\mathrm{H} 3$ arginine 2 (H3R2me2a), which also affects methylation of neighboring $\mathrm{K} 4{ }^{79}$. Localizing $\mathrm{H} 3 \mathrm{R} 2 \mathrm{me} 2 \mathrm{a}$ suggests that it is excluded from active promoters and thus provides evidence for crosstalk between these two marks. The essential nucleosome remodeling factor NURF can also bind to H3K4me3 and thus may provide local, promoter associated chromatin remodeling activity ${ }^{80,81}$. Multiple additional factors, including inhibitor of growth (ING) proteins and the 
chromatin associated factor PHF13/SPOC1, were identified as readers of H3K4me3 that might be associated with gene transcription 5, 82, 83. Thus, the loss of H3K4 methylation at promoters is likely to have multiple consequences, many are consistent with reduced gene expression.

In hematopoietic cells, the loss of Ash2I resulted in a cell cycle arrest in late G2/early $\mathrm{M}$ phase and as a consequence differentiation to mature cells was inhibited ${ }^{13}$. Similarly, Dpy30 is necessary for hematopoietic cell proliferation and differentiation. Dpy30 KO hematopoietic cells also accumulate at the HSPC state ${ }^{12,84}$, suggesting that the main phenotype observed upon loss of either Ash2l or Dpy30 is due to the inactivation of KMT2 complexes. However, unlike in HSPCs, the fibroblasts did not accumulate in any particular cell cycle phase, with the exception of a small increase in $S$ phase cells (Figs. 1). Among the downregulated genes were many that encode cell cycle regulators, such as different cyclins, Cdk1 and E2F transcription factors ${ }^{85}$, and replication factors, including 4 out of 6 minichromosome maintenance proteins (Mcm) (Table S2). The Mcm2-7 complex functions together with additional proteins as essential helicase during DNA double strand opening ${ }^{86}$. Thus, the observed cell cycle phenotype is in agreement with the repression of genes that encode essential regulators of both cell cycle progression and replication. We assume that depending on the process that becomes limiting first, cells arrest in different phases of the cell cycle.

The phenotypic outcome of Ash2l loss in iMEF cells is senescence. This is a highly heterogeneous process when comparing different cell types and conditions. Stressinduced irreversible proliferation arrest and resistance to both mitogenic and oncogenic stimuli have been suggested to best define the senescent state ${ }^{22,33,40}$. Also the observed cell cycle arrest and the lack of apoptosis are features of senescent cells ${ }^{87}$. Typical stressors include excessive replication (replication stress), the induction of oncogenes (oncogene-induced senescence), and DNA damage (e.g. ionizing radiation-induced senescence). These result in both activation and repression of distinct sets of genes. One prominent consequence is the activation of SASP, which has been argued to occur in all senescent cells ${ }^{22,32,33}$. SASP genes encode a broad repertoire of different proteins, including cytokines, growth factors and matrix metalloproteinases. These affect the physiology of neighboring cells and are also 
responsible for many of the patho-physiological consequences as documented for example in cancer ${ }^{88,89}$. While genes associated with SASP, such as Cxcl1, Cxcl16 and IGFBP-6 were slightly upregulated, albeit not significantly (Suppl. Table S1), we did not observe a broad SASP response. IL6, IL7 and $\mathrm{CC} / 2$, prominent members of SASP, were initially downregulated upon loss of Ash2I, while at later time points we observed an increase in Ccl2 by RT-qPCR (Fig. 5), while these genes were not affected in RNA-seq (Suppl. Table S1). We interpret this as an attempt to activate SASP as part of the senescence response to downregulation of Ash2l but activation of gene expression is inefficient or not possible once H3K4 methylation is lacking. This is also consistent with the finding that MLL1/KMT2A is essential for SASP ${ }^{90}$.

MAP kinases, including p38MAPK, have been described to be important signaling molecules during senescence and to activate SASP 91, 92, 93, 94. Indeed, we observed activation of p38MAPK (Fig. 2). Moreover, the activation of PI3 kinases has been connected to anti-apoptosis in senescent cells as inhibiting this kinase and downstream effectors are senolytic ${ }^{27,28,95}$. Inhibiting MAP kinases by Dasatinib ${ }^{96}$ and PI3 kinases by Compound 15e, Wortmannin and Quercetin showed senolytic effects in $\mathrm{KO} 2$ cells, consistent with these being senescent upon loss of Ash2l.

A number of reports have indicated that gene repression is also associated with senescence. We compared our downregulated genes with those that are associated with senescence in a number of different setups in human primary and cancer cells ${ }^{34}$, $35,36,37$. We identified a group of 28 genes that were in common (Fig. 4). GO analysis identified senescence, cell cycle and stress as relevant terms. Several of the genes in this group encode proteins directly linked to senescence. This includes HMGB2, which downregulated early in senescence ${ }^{35}$, and during aging ${ }^{63}$. Conversely, the expression of HMGB2 is induced when cell enter the cell cycle form a quiescent state ${ }^{64}$. A role of HMGB2 in senescence is further supported by its role in inhibiting the spreading of heterochromatin, which ensures expression of SASP genes 65. However, the expression of HMGB2 was not sufficient to affect senescence in iMEF cells (Fig. 5).

Moreover, Cenpa, Neil3 and cyclin A2 can interfere with senescence 51, 97, 98. In addition, several other member of the $M$ group seem to affect senescence indirectly. Of particular interest is that many of these genes are regulated by FOXM1, as listed 
above. Indeed, the expression of FOXM1 in iMEF cells slowed the appearance of senescence cells by 2 days (Fig. 5).

Of note is that previous studies have suggested a link of KMT2 complex subunits to senescence. MLL1/KMT2A is frequently translocated in leukemias ${ }^{99}$. The MLL1-ENL fusion protein, which promotes aberrant proliferation, provokes a DNA damage response and senescence, initially restricting tumor cell proliferation ${ }^{100}$. The knockdown of SET1A/KMT2F, which is frequently overexpressed in tumors, results in mitotic defects and senescence ${ }^{101}$. In summary, we identified the trithorax protein Ash2l as a regulator of senescence in fibroblasts. The Ash2/ KO MEFs displayed many hallmarks of senescent cells but lacked the typical activation of genes encoding SASP factors. Instead, we find that the downregulation of $\mathrm{M}$ group genes provide a signature that seems to be relevant for many different senescent phenotypes. 


\section{MATERIALS AND METHODS}

\section{Embryonic fibroblasts}

Primary fibroblast cultures from littermate embryos (d.p.c. 13.5) were prepared using mice harboring wild-type or exon 4-floxed alleles of Ash2l ${ }^{14}$ and a single copy of the constitutively expressed transgene CAGGCre-ER ${ }^{T M}$ (strain 004682, The Jackson Laboratory) comprising a fusion between Cre recombinase and the G525R mutant of the mouse estrogen receptor (pMEF, WT: Ash2//++/Cre-ER and KO: Ash2ff//fl/Cre-ER). For the generation of immortalized fibroblast cultures (iMEF) the cells were infected with a retrovirus encoding an shRNA against p19Arf 23, 24 and a Blasticidin resistance gene used for the initial selection of infected cells $(10 \mu \mathrm{g} / \mathrm{ml}$ Blasticidin, Invivogen, antbl). MEF cells were cultivated in DMEM (Thermo Fisher Scientific, 61965059) supplemented with $10 \%$ heat-inactivated fetal bovine serum (FBS, Thermo Fisher Scientific, 10270106) and 1\% penicillin/streptomycin (Thermo Fisher Scientific, 15070063).

KO2 cells of an early passage were infected with lentiviruses expressing HMGB2eYFP or FOXM1-eYFP fusion proteins and selected with $20 \mu \mathrm{g} / \mathrm{ml}$ hygromycin B (Goldbio Biotechnology, H-270-1). Pools of cells were then cultured in the presence of hygromycin. The expression of FOXM1-eYFP and HMGB2-eYFP was induced by adding $1 \mu \mathrm{g} / \mathrm{ml}$ Doxycycline (Sigma Aldrich, D9891).

\section{Induction of recombination}

At day 0 cells were treated with $5 \mathrm{nM}$ 4-Hydroxytamoxifen (+HOT) (Tocris, 3412) or with vehicle (-HOT, 100\% ethanol). Thereafter cells were passaged when needed to maintain subconfluency or solely supplied with new medium with the addition of HOT or vehicle as before.

\section{End-point PCR of genomic DNA}

Genomic DNA was isolated using the High Pure PCR Template Preparation Kit (Roche, 11796828001) and the PCR performed using the ALLin Red Taq MasterMix (highQu, PCM0201) according to the manufacturers' instructions. Fragments were analyzed by agarose gel electrophoresis. 


\section{RT-qPCR}

Total RNA was isolated with the High Pure RNA Isolation Kit (Roche, 11828665001) and cDNA synthesized with the QuantiTect Reverse Transcription Kit (Qiagen, 205314). A SYBR Green reaction mix (QuantiNova, Qiagen 208054) was employed for the quantitative PCR (qPCR) analyses in a RotorGene 6000 cycler (Corbett/Qiagen). For the individual transcripts, QuantiTect Primer Assays (Qiagen) or primers designed with the Primer3 software (http://primer3.ut.ee) were employed as indicated (see Table 1). The efficiency of all primers used was higher than $95 \%$. The PCR reactions were performed with an initial step at $95^{\circ} \mathrm{C}$ for 2 minutes, followed by 40 cycles at $95^{\circ} \mathrm{C}$ for $10 \mathrm{~s}, 60^{\circ} \mathrm{C}$ for $10 \mathrm{~s}$, and $72^{\circ} \mathrm{C}$ for $5 \mathrm{~s}$ and a melting curve analysis. Fold changes in expression were calculated according to Pfaffl ${ }^{102}$ taking into account the respective primer reaction efficiencies and using $\beta$-glucuronidase (Gusb) as the reference gene as its expression was only little or not affected by the HOT treatment.

\section{RNA-seq}

From parallel cell cultures the number of cells was determined and RNA purified as noted above. The cell number was used to adjust the amount of ERCC RNA Spike-In Mix (ThermoFisher Scientific, 4456740). Generation of RNA-seq libraries (TruSeq Stranded Total RNA Sample Library Prep, Illumina, 20020596) and next-generation sequencing (NextSeq 500/550 High Output Kit v2.5, 150 cycles, Illumina, 20024907) were performed by the Genomics Core Facility of the Interdisciplinary Center for Clinical Research (IZKF) Aachen of the Faculty of Medicine at RWTH Aachen University.

\section{Western Blots}

Cells were lysed on ice in RIPA buffer (10 mM Tris/HCl, pH 7.4, $150 \mathrm{mM} \mathrm{NaCl}, 1 \%$ Nonidet P-40, 1\% deoxycholic acid, 0.1\% SDS, protease inhibitor cocktail (1xPIC, Merck, P8340)), containing $10 \mathrm{mM}$ sodium butyrate. After sonication and centrifugation, the protein contents of the supernatants were determined prior to SDSPAGE and immunoblotting. To verify equal loading the membranes were reversibly stained with $0.2 \%$ Ponceau S. The antibodies were applied in $5 \%$ low-fat milk, $0.05 \%$ Tween20 in PBS. For analyzing p38 phosphorylation, the lysis buffer contained additionally a phosphatase inhibitor cocktail ( $1 \mathrm{mM}$ ortho-vanadate, $50 \mathrm{nM}$ okadaic acid, $50 \mathrm{nM}$ ß-phospho-glycerol, $25 \mathrm{mM} \mathrm{NaF}, 5 \mathrm{mM}$ EGTA). The antibodies were 
applied in 5\% BSA, $0.05 \%$ Tween20 in PBS. The blots were developed with the SuperSignal West Femto Chemiluminescence Substrate (ThermoFisher Scientific, 34094). For details of the antibodies see Table 2.

\section{In vitro SAM assay}

Cell lysates were prepared in Co-IP buffer (10 mM HEPES, pH 7.5, 50 mM NaCl, 30 $\mathrm{mM} \mathrm{Na}_{4} \mathrm{P}_{2} \mathrm{O}_{7}, 50 \mathrm{mM} \mathrm{NaF}$, 0.2\% (v/v) Triton X-100, 10\% (v/v) glycerol, $5 \mu \mathrm{M} \mathrm{ZnCl}_{2}$, 1xPIC). Lysed cells were mixed vigorously for $45 \mathrm{sec}$ and centrifuged at $16,000 \mathrm{xg}$ and $4^{\circ} \mathrm{C}$ for $20 \mathrm{~min}$. The protein concentrations of the supernatants were measured and adjusted accordingly. Aliquots were retained for direct Western blot analysis (Input) and otherwise subjected to immunoprecipitation (IP) with protein A-coupled Sepharose beads (Merck, 17-5280-02) pre-incubated with $2 \mu \mathrm{g}$ anti-RbBP5 antibody or $\operatorname{lgG}$ at $4{ }^{\circ} \mathrm{C}$ for 2 hours. Protein-antibody-bead complexes were washed three times with Co-IP buffer and twice with SAM assay buffer (50 mM Tris- $\mathrm{HCl}(\mathrm{pH} 8.0), 5 \mathrm{mM} \mathrm{MgCl} 2,50 \mathrm{mM}$ $\mathrm{NaCl}, 1 \mathrm{mM}$ DTT, 1xPIC). Afterwards $2 \mu \mathrm{g}$ of recombinant human Histone H3.1 (New England BioLabs, M2503), $100 \mu \mathrm{M}$ S-(5'-adenosyl)-L-methionine chloride dihydrochloride (SAM, Merck, A7007) used as a primary methyl donor molecule, dissolved in $30 \mu \mathrm{l}$ SAM assay buffer were added to the beads and incubated for $1 \mathrm{~h}$ at $31^{\circ} \mathrm{C}$ with agitation. Subsequently the beads were heated in sample buffer (40 mM Tris $\mathrm{pH}$ 6.8, $10 \%$ Glycerol, 2\% SDS, bromophenol blue) at $95^{\circ} \mathrm{C}$ for $10 \mathrm{~min}$ and used for SDS-PAGE and immunoblotting.

\section{Immunoprecipitation (GFP-Trap)}

eYFP-tagged fusion proteins were immunoprecipitated using anti-GFP magnetic agarose beads (Chromotek, gtma-20). After induction of gene expression of lentiviral transduced $\mathrm{KO} 2$ cells with $1 \mu \mathrm{g} / \mathrm{ml}$ doxycycline, cells were harvested and pelleted. Lysis was performed with ice cold RIPA buffer as described above. A fraction of the lysate was used as input, while the rest was subjected to IP with $5 \mu$ l of magnetic beads. IP samples are incubated on an overhead rotator at $4^{\circ} \mathrm{C}$ for 2 hours and subsequently washed three times in RIPA buffer. The beads were collected in magnetic stand and proteins solubilized in loading buffer as described above. 


\section{Immunofluorescence}

Immortalized WT and KO iMEF cells were treated with HOT or vehicle for 5 days, fixed in paraformaldehyde (4\% in PBS) at RT for 20 min and permeabilized at RT with TritonX100 (0.2\% in PBS) for 5 min. Subsequently, unspecific binding sites were blocked with $20 \%$ horse serum (HS) in PBS at $37^{\circ} \mathrm{C}$ for $30 \mathrm{~min}$. All antibodies were applied in $20 \% \mathrm{HS} / \mathrm{PBS}$ : the primary antibody (specific for Ash2l) at $37^{\circ} \mathrm{C}$ for $45 \mathrm{~min}$ and the secondary antibody (anti-rat Alexa Fluor 488 ) at $37^{\circ} \mathrm{C}$ for $30 \mathrm{~min}$. On parallel slides primary antibodies (anti-H3K4me3 or anti- $\gamma-\mathrm{H} 2 \mathrm{AX}$ ) were incubated overnight at $4^{\circ} \mathrm{C}$ followed by the secondary antibody (anti-rat or anti-rabbit Alexa Fluor 555 ) at $37^{\circ} \mathrm{C}$ for $30 \mathrm{~min}$. After each incubation the cells were washed 3 times with PBS. Finally, the nuclei were visualized with Hoechst 33258 (Merck, B2883, $2 \mu \mathrm{g} / \mathrm{ml}$ in H2O at RT for 5 $\min )$.

\section{Cell proliferation and SA- $\beta$-Galactosidase staining}

To measure the proliferation, pMEF and IMEF cells were seeded in triplicates, treated with HOT or vehicle and counted at the days indicated using the CASY® Technology Cell Counter (Innovatis) with three measurements per sample.

Staining for senescence-associated $\beta$-galactosidase activity (SA- $\beta$-Gal) was performed with cells fixed with glutaraldehyde (0.5\% in PBS, RT for $10 \mathrm{~min})$ 103, 104, 105 . After washing twice with PBS containing $2 \mathrm{mM} \mathrm{MgCl}_{2}(\mathrm{pH} 6.0)$, the staining solution (5 $\mathrm{mM}$ K-ferrocyanide, $5 \mathrm{mM}$ K-ferricyanide, $1 \mathrm{mg} / \mathrm{ml}$ X-gal in $\mathrm{MgCl}_{2} / \mathrm{PBS}, \mathrm{pH}$ 6.0) was applied at $4^{\circ} \mathrm{C}$ overnight. After washing with $\mathrm{H}_{2} \mathrm{O}$, the percentage of blue cells vs. the total number of cells was determined.

The senolytics Dasitinib (Cayman Chemical, 11498), Quercetin (Cayman Chemical, 10005169), Compound15e (Enzo Life Science, ALX 270-455) and Wortmannin (Merck, 681675) were dissolved in DMSO and added to cultured cells after 5 days of HOT treatment. Wortmannin was re-added daily.

\section{Flow cytometry analyses}

Cell cycle distribution of iMEF cells was analyzed using flow cytometry using the Foxp3/Transcription Factor Staining Buffer Set (eBioscience, 00-5523) according to the manufacturer's instructions. After trypsinization, cell pellets were resuspended in 
$200 \mu \mathrm{l}$ PBS and $800 \mu \mathrm{l}$ of Fixation/Permeabilization Buffer under constant vortexing. After incubation at RT for $15 \mathrm{~min}, 2 \mathrm{ml}$ of Permeabilisation Buffer was added and the cells were centrifuged with $380 \times \mathrm{g}$ at RT for $3 \mathrm{~min}$. For cell cycle distribution the fixed cells were resuspended in Hoechst 33258 (Merck, B2883 $1 \mu \mathrm{g} / \mathrm{ml} \mathrm{H} 2 \mathrm{O}$ ). For nocodazole treatment, the iMEF cells were incubated for 7 days with HOT or vehicle and with $100 \mathrm{ng} / \mathrm{ml}$ nocodazole (Merck, M1404) in DMSO or with vehicle for $18 \mathrm{~h}$ before sample collection. Apoptosis was assessed using the FITC Annexin V Apoptosis Detection Kit and with propidium iodide staining (Immunostep, ANXVKF) according to the manufacturer's protocol. Measurements were performed using a FACSCanto II system (BD Biosciences) and analyzed with FlowJo software or Flowing Software 2.

\section{Quantification and statistical analysis}

Error bars represent standard deviation (SD) of the mean, unless otherwise indicated. Statistical significance was evaluated by multiple t-test using GraphPadPrism software, unless otherwise indicated.

\section{Bioinformatics}

For RNA-seq, we trimmed sequences using Trim Galore (http://www.bioinformatics.babraham.ac.uk/projects/trim galore/). The sequences were aligned against the reference genome (UCSC mm9) using STAR for RNA-seq 106. We used Gencode/ENSEMBL annotation (Mouse Release M1) to build a gene count matrix with featureCounts ${ }^{107}$. Next, we used DEseq2 ${ }^{108}$ to perform differential expression analysis. Genes were normalized only by ERCC (External RNA Controls Consortium) counts. Differentially regulated genes per each cell type and differential promoters are listed in Suppl. Table S1.

GO term/pathway enrichment analyses were performed using the Metascape interface tool (http://metascape.org/gp/index.html) ${ }^{109}$. For the $\mathrm{GO}$ analysis in Figure 4 we employed g:Profiler ${ }^{110}$.

Sequencing data of the RNA-seq experiments have been deposited in Gene Expression Omnibus (Suppl. Table S1:

https://www.ncbi.nlm.nih.gov/geo/query/acc.cgi, accession number GSE165458, password izyrokiwhropdwz). 


\section{ACKNOWLEDGMENTS}

We thank Dr. M. Eilers (University of Würzburg, Germany) for providing the siRNA expression construct that targets the p19ARF mRNA, J. Stahl for expert technical assistance and L. Gan und J. Hübner of the Genomics Facility of the Interdisciplinary Center for Clinical Research (IZKF) Aachen, Faculty of Medicine, RWTH Aachen University for support in the gene expression analysis. Simulations were performed with computing resources granted by RWTH Aachen University under project rwth0751 (to M.B.). The work was funded in part by grants from the German Research Foundation DFG (LU466/17-1 and 17-2 to B.L.) and the Interdisciplinary Center for Clinical Research (IZKF) Aachen (to I.C.).

\section{AUTHOR CONTRIBUTIONS}

A.B., A.T.S., R.S.B., W.L., P.B. and J.L.F. performed the wet experiments; R.S.B., C.C.K., M.B. and I.C. carried out bioinformatics analyses; J.L.F and B.L. developed the project; A.B., R.S.B., C.C.K., M.B., I.C., J.L.F and B.L. analyzed data; J.L.F, I.C. and B.L. wrote the initial version of the paper; all authors read and approved the final manuscript.

\section{ADDITIONAL INFORMATION}

Supplementary information: 4 Figures, 2 Tables

Competing interests: The authors declare no competing interests.

Ethical approval and informed consent: All procedures were approved by the Institute for Laboratory Animal Science and the local government (LANUV NRW, AZ 84-02.04.2013.A182) in accordance with German and EU regulations (also indicated in Material and Methods section). 


\section{REFERENCES}

1. Kornberg RD, Lorch Y. Perspective Primary Role of the Nucleosome. Mol Cell 79, 371-375 (2020).

2. Zhou KD, Gaullier G, Luger K. Nucleosome structure and dynamics are coming of age. Nature Structural \& Molecular Biology 26, 3-13 (2019).

3. Zentner GE, Henikoff S. Regulation of nucleosome dynamics by histone modifications. Nature structural \& molecular biology 20, 259-266 (2013).

4. Morgan MAJ, Shilatifard A. Reevaluating the roles of histone-modifying enzymes and their associated chromatin modifications in transcriptional regulation. Nat Genet 52, 1271-1281 (2020).

5. Bochynska A, Luscher-Firzlaff J, Luscher B. Modes of Interaction of KMT2 Histone H3 Lysine 4 Methyltransferase/COMPASS Complexes with Chromatin. Cells 7, (2018).

6. Shilatifard A. The COMPASS family of histone H3K4 methylases: mechanisms of regulation in development and disease pathogenesis. Annu Rev Biochem 81, 65-95 (2012).

7. Rao RC, Dou Y. Hijacked in cancer: the KMT2 (MLL) family of methyltransferases. Nat Rev Cancer 15, 334-346 (2015).

8. Jiang $\mathrm{H}$. The complex activities of the SET1/MLL complex core subunits in development and disease. Bba-Gene Regul Mech 1863, (2020). 
9. Hughes AL, Kelley JR, Klose RJ. Understanding the interplay between CpG island-associated gene promoters and H3K4 methylation. Biochim Biophys Acta Gene Regul Mech 1863, 194567 (2020).

10. Stoller JZ, et al. Ash2l interacts with $\mathrm{Tbx1}$ and is required during early embryogenesis. Exp Biol Med (Maywood) 235, 569-576 (2010).

11. Bertero $A$, et al. Activin/nodal signaling and NANOG orchestrate human embryonic stem cell fate decisions by controlling the H3K4me3 chromatin mark. Genes Dev 29, 702-717 (2015).

12. Yang Z, Shah $\mathrm{K}$, Khodadadi-Jamayran A, Jiang $\mathrm{H}$. Dpy30 is critical for maintaining the identity and function of adult hematopoietic stem cells. J Exp Med 213, 2349-2364 (2016).

13. Luscher-Firzlaff $\mathrm{J}$, et al. Hematopoietic stem and progenitor cell proliferation and differentiation requires the trithorax protein Ash2l. Sci Rep 9, 8262 (2019).

14. Liang WL, Luscher-Firzlaff J, Ullius A, Schneider U, Longerich T, Luscher B. Loss of the epigenetic regulator Ash2l results in desintegration of hepatocytes and liver failure. Int J Clin Exp Patho 9, 5167-5175 (2016).

15. Shearn A. The ash-1, ash-2 and trithorax genes of Drosophila melanogaster are functionally related. Genetics 121, 517-525 (1989).

16. Shearn A, Hersperger E, Hersperger G. Genetic studies of mutations at two loci of Drosophila melanogaster which cause a wide variety of homeotic transformations. Rouxs Arch Dev Biol 196, 231-242 (1987). 
17. Ingham PW. Trithorax: A new homoeotic mutation ofDrosophila melanogaster : II. The role oftrx (+) after embryogenesis. Wilehm Roux Arch Dev Biol 190, 365-369 (1981).

18. Poreba E, Lesniewicz K, Durzynska J. Aberrant Activity of Histone-Lysine NMethyltransferase 2 (KMT2) Complexes in Oncogenesis. Int J Mol Sci 21, (2020).

19. Ullius $A$, et al. The interaction of MYC with the trithorax protein $\mathrm{ASH} 2 \mathrm{~L}$ promotes gene transcription by regulating H3K27 modification. Nucleic Acids Res 42, 6901-6920 (2014).

20. Luscher-Firzlaff $\mathrm{J}$, et al. The human trithorax protein $\mathrm{hASH} 2$ functions as an oncoprotein. Cancer Res 68, 749-758 (2008).

21. Di Micco R, Krizhanovsky V, Baker D, d'Adda di Fagagna F. Cellular senescence in ageing: from mechanisms to therapeutic opportunities. Nat Rev Mol Cell Biol 22, 75-95 (2021).

22. Sikora E, Bielak-Zmijewska A, Mosieniak G. A common signature of cellular senescence; does it exist? Ageing Res Rev 71, 101458 (2021).

23. Carnero A, Hudson JD, Price CM, Beach DH. p16INK4A and p19ARF act in overlapping pathways in cellular immortalization. Nat Cell Biol 2, 148-155 (2000).

24. Tzatsos A, Pfau R, Kampranis SC, Tsichlis PN. Ndy1/KDM2B immortalizes mouse embryonic fibroblasts by repressing the Ink4a/Arf locus. Proc Natl Acad Sci $U$ $S$ A 106, 2641-2646 (2009). 
25. Luscher B, Brizuela L, Beach D, Eisenman RN. A Role for the P34cdc2 Kinase and Phosphatases in the Regulation of Phosphorylation and Disassembly of Lamin-B2 during the Cell-Cycle. Embo Journal 10, 865-875 (1991).

26. Gasek NS, Kuchel GA, Kirkland JL, Xu M. Strategies for Targeting Senescent Cells in Human Disease. Nat Aging 1, 870-879 (2021).

27. Schafer MJ, et al. Cellular senescence mediates fibrotic pulmonary disease. Nat Commun 8, 14532 (2017).

28. Zhu Y, et al. The Achilles' heel of senescent cells: from transcriptome to senolytic drugs. Aging Cell 14, 644-658 (2015).

29. Bain J, et al. The selectivity of protein kinase inhibitors: a further update. Biochem J 408, 297-315 (2007).

30. Folkes AJ, et al. The identification of 2-(1H-indazol-4-yl)-6-(4-methanesulfonylpiperazin-1-ylmethyl)-4-morpholin-4-yl-t hieno[3,2-d]pyrimidine (GDC-0941) as a potent, selective, orally bioavailable inhibitor of class I PI3 kinase for the treatment of cancer. J Med Chem 51, 5522-5532 (2008).

31. Anerillas C, Abdelmohsen K, Gorospe M. Regulation of senescence traits by MAPKs. Geroscience 42, 397-408 (2020).

32. Kuilman T, Peeper DS. Senescence-messaging secretome: SMS-ing cellular stress. Nat Rev Cancer 9, 81-94 (2009).

33. Gorgoulis V, et al. Cellular Senescence: Defining a Path Forward. Cell 179, 813827 (2019). 
34. Lackner DH, Hayashi MT, Cesare AJ, Karlseder J. A genomics approach identifies senescence-specific gene expression regulation. Aging Cell 13, 946-950 (2014).

35. Zirkel A, et al. HMGB2 Loss upon Senescence Entry Disrupts Genomic Organization and Induces CTCF Clustering across Cell Types. Mol Cell 70, 730-744 e736 (2018).

36. Casella G, et al. Transcriptome signature of cellular senescence. Nucleic Acids Res 47, 7294-7305 (2019).

37. Jochems $\mathrm{F}$, et al. The Cancer SENESCopedia: A delineation of cancer cell senescence. Cell Rep 36, 109441 (2021).

38. Lee $\mathrm{S}$, et al. Virus-induced senescence is a driver and therapeutic target in COVID-19. Nature 599, 283-289 (2021).

39. Garcia-Muse T, Aguilera A. Transcription-replication conflicts: how they occur and how they are resolved. Nat Rev Mol Cell Biol 17, 553-563 (2016).

40. Sharpless NE, Sherr CJ. Forging a signature of in vivo senescence. Nat Rev Cancer 15, 397-408 (2015).

41. Rogakou EP, Pilch DR, Orr AH, Ivanova VS, Bonner WM. DNA double-stranded breaks induce histone H2AX phosphorylation on serine 139. Journal of Biological Chemistry 273, 5858-5868 (1998).

42. Burma S, Chen BP, Murphy M, Kurimasa A, Chen DJ. ATM phosphorylates histone $\mathrm{H} 2 \mathrm{AX}$ in response to DNA double-strand breaks. Journal of Biological Chemistry 276, 42462-42467 (2001). 
43. Hernandez-Segura A, de Jong TV, Melov S, Guryev V, Campisi J, Demaria M. Unmasking Transcriptional Heterogeneity in Senescent Cells. Curr Biol 27, 2652-2660 e2654 (2017).

44. Thiru $\mathrm{P}$, et al. Kinetochore genes are coordinately up-regulated in human tumors as part of a FoxM1-related cell division program. Mol Biol Cell 25, 1983-1994 (2014).

45. Shirakawa J, et al. Insulin Signaling Regulates the FoxM1/PLK1/CENP-A Pathway to Promote Adaptive Pancreatic beta Cell Proliferation. Cell Metab 25, 868882 e865 (2017).

46. Yang YF, et al. PDZ binding kinase, regulated by FoxM1, enhances malignant phenotype via activation of beta-Catenin signaling in hepatocellular carcinoma. Oncotarget 8, 47195-47205 (2017).

47. Wang IC, et al. Forkhead box M1 regulates the transcriptional network of genes essential for mitotic progression and genes encoding the SCF (Skp2-Cks1) ubiquitin ligase. Mol Cell Biol 25, 10875-10894 (2005).

48. Vaz S, et al. FOXM1 repression increases mitotic death upon antimitotic chemotherapy through BMF upregulation. Cell Death Dis 12, 542 (2021).

49. Cosentino C, Mostoslavsky R. Sirtuin to the rescue: SIRT2 extends life span of BubR1 mice. EMBO J 33, 1417-1419 (2014).

50. North BJ, et al. SIRT2 induces the checkpoint kinase BubR1 to increase lifespan. EMBO J 33, 1438-1453 (2014). 
51. Maehara K, Takahashi K, Saitoh S. CENP-A reduction induces a p53dependent cellular senescence response to protect cells from executing defective mitoses. Mol Cell Biol 30, 2090-2104 (2010).

52. Wang X, Krupczak-Hollis K, Tan Y, Dennewitz MB, Adami GR, Costa RH. Increased hepatic Forkhead Box M1B (FoxM1B) levels in old-aged mice stimulated liver regeneration through diminished p27Kip1 protein levels and increased Cdc25B expression. J Biol Chem 277, 44310-44316 (2002).

53. Luscher-Firzlaff JM, Lilischkis R, Luscher B. Regulation of the transcription factor FOXM1c by Cyclin E/CDK2. FEBS Lett 580, 1716-1722 (2006).

54. Kalinichenko VV, et al. Ubiquitous expression of the forkhead box M1B transgene accelerates proliferation of distinct pulmonary cell types following lung injury. J Biol Chem 278, 37888-37894 (2003).

55. Sadasivam S, Duan S, DeCaprio JA. The MuvB complex sequentially recruits B-Myb and FoxM1 to promote mitotic gene expression. Genes Dev 26, 474-489 (2012).

56. Branigan TB, et al. MMB-FOXM1-driven premature mitosis is required for $\mathrm{CHK} 1$ inhibitor sensitivity. Cell Rep 34, 108808 (2021).

57. Lee $\mathrm{OH}$, et al. Sirtuin 6 deficiency induces endothelial cell senescence via downregulation of forkhead box M1 expression. Aging (Albany NY) 12, 20946-20967 (2020).

58. Macedo JC, et al. FoxM1 repression during human aging leads to mitotic decline and aneuploidy-driven full senescence. Nat Commun 9, 2834 (2018). 
59. Choi YW, et al. Abrogation of B-Raf(V600E) induced senescence by FoxM1 expression. Biochem Biophys Res Commun 516, 866-871 (2019).

60. Smirnov A, et al. FOXM1 regulates proliferation, senescence and oxidative stress in keratinocytes and cancer cells. Aging (Albany NY) 8, 1384-1397 (2016).

61. Anders $L$, et al. A systematic screen for CDK4/6 substrates links FOXM1 phosphorylation to senescence suppression in cancer cells. Cancer Cell 20, 620-634 (2011).

62. Voong CK, Goodrich JA, Kugel JF. Interactions of HMGB Proteins with the Genome and the Impact on Disease. Biomolecules 11, (2021).

63. Lawrence I, et al. Correlations between age, functional status, and the senescence-associated proteins HMGB2 and p16(INK4a). Geroscience 40, 193-199 (2018).

64. Kimura A, Matsuda T, Sakai A, Murao N, Nakashima K. HMGB2 expression is associated with transition from a quiescent to an activated state of adult neural stem cells. Dev Dyn 247, 229-238 (2018).

65. Aird KM, et al. HMGB2 orchestrates the chromatin landscape of senescenceassociated secretory phenotype gene loci. J Cell Biol 215, 325-334 (2016).

66. Patel A, Dharmarajan V, Vought VE, Cosgrove MS. On the mechanism of multiple lysine methylation by the human mixed lineage leukemia protein-1 (MLL1) core complex. J Biol Chem 284, 24242-24256 (2009). 
67. Southall SM, Wong PS, Odho Z, Roe SM, Wilson JR. Structural basis for the requirement of additional factors for MLL1 SET domain activity and recognition of epigenetic marks. Mol Cell 33, 181-191 (2009).

68. Avdic V, et al. Structural and biochemical insights into MLL1 core complex assembly. Structure 19, 101-108 (2011).

69. Zhang $\mathrm{P}$, et al. A phosphorylation switch on RbBP5 regulates histone H3 Lys4 methylation. Genes Dev 29, 123-128 (2015).

70. Steward MM, Lee JS, O'Donovan A, Wyatt M, Bernstein BE, Shilatifard A. Molecular regulation of $\mathrm{H} 3 \mathrm{~K} 4$ trimethylation by $\mathrm{ASH} 2 \mathrm{~L}$, a shared subunit of $\mathrm{MLL}$ complexes. Nat Struct Mol Biol 13, 852-854 (2006).

71. Dou $\mathrm{Y}$, et al. Regulation of MLL1 H3K4 methyltransferase activity by its core components. Nat Struct Mol Biol 13, 713-719 (2006).

72. Eberl HC, Spruijt CG, Kelstrup CD, Vermeulen M, Mann M. A map of general and specialized chromatin readers in mouse tissues generated by label-free interaction proteomics. Mol Cell 49, 368-378 (2013).

73. Kim J, et al. Tudor, MBT and chromo domains gauge the degree of lysine methylation. EMBO Rep 7, 397-403 (2006).

74. Yun M, Wu J, Workman JL, Li B. Readers of histone modifications. Cell Res 21, 564-578 (2011).

75. Morgan MAJ, et al. A cryptic Tudor domain links BRWD2/PHIP to COMPASSmediated histone H3K4 methylation. Genes Dev 31, 2003-2014 (2017). 
76. Patel DJ, Wang Z. Readout of epigenetic modifications. Annu Rev Biochem 82, 81-118 (2013).

77. Vermeulen $\mathrm{M}$, et al. Selective Anchoring of TFIID to Nucleosomes by Trimethylation of Histone H3 Lysine 4. Cell 131, 58-69 (2007).

78. van Ingen $\mathrm{H}$, et al. Structural insight into the recognition of the H3K4me3 mark by the TFIID subunit TAF3. Structure 16, 1245-1256 (2008).

79. Guccione $\mathrm{E}$, et al. Methylation of histone H3R2 by PRMT6 and H3K4 by an MLL complex are mutually exclusive. Nature 449, 933-937 (2007).

80. Wysocka J, et al. A PHD finger of NURF couples histone H3 lysine 4 trimethylation with chromatin remodelling. Nature 442, 86-90 (2006).

81. Alkhatib SG, Landry JW. The nucleosome remodeling factor. FEBS Lett $\mathbf{5 8 5}$, 3197-3207 (2011).

82. Tallen G, Riabowol K. Keep-ING balance: tumor suppression by epigenetic regulation. FEBS Lett 588, 2728-2742 (2014).

83. Chung HR, et al. PHF13 is a molecular reader and transcriptional co-regulator of H3K4me2/3. Elife 5, (2016).

84. Yang Z, et al. The DPY30 subunit in SET1/MLL complexes regulates the proliferation and differentiation of hematopoietic progenitor cells. Blood 124, 20252033 (2014).

85. Malumbres M. Cyclin-dependent kinases. Genome Biol 15, 122 (2014). 
86. Burgers PMJ, Kunkel TA. Eukaryotic DNA Replication Fork. Annual Review of Biochemistry, Vol 86 86, 417-438 (2017).

87. Kirkland JL, Tchkonia T. Cellular Senescence: A Translational Perspective. EBioMedicine 21, 21-28 (2017).

88. Tchkonia T, Zhu Y, van Deursen J, Campisi J, Kirkland JL. Cellular senescence and the senescent secretory phenotype: therapeutic opportunities. J Clin Invest 123, 966-972 (2013).

89. Lee S, Schmitt CA. The dynamic nature of senescence in cancer. Nat Cell Biol 21, 94-101 (2019).

90. Capell BC, et al. MLL1 is essential for the senescence-associated secretory phenotype. Genes Dev 30, 321-336 (2016).

91. Haq $\mathrm{R}$, et al. Constitutive p38HOG mitogen-activated protein kinase activation induces permanent cell cycle arrest and senescence. Cancer Res 62, 5076-5082 (2002).

92. Wang W, et al. Sequential activation of the MEK-extracellular signal-regulated kinase and MKK3/6-p38 mitogen-activated protein kinase pathways mediates oncogenic ras-induced premature senescence. Mol Cell Biol 22, 3389-3403 (2002).

93. Freund A, Patil CK, Campisi J. p38MAPK is a novel DNA damage responseindependent regulator of the senescence-associated secretory phenotype. EMBO $J$ 30, 1536-1548 (2011). 
94. Slobodnyuk K, et al. Autophagy-induced senescence is regulated by p38alpha signaling. Cell Death Dis 10, 376 (2019).

95. Baar MP, et al. Targeted Apoptosis of Senescent Cells Restores Tissue Homeostasis in Response to Chemotoxicity and Aging. Cell 169, 132-147 e116 (2017).

96. Greuber EK, Smith-Pearson P, Wang J, Pendergast AM. Role of ABL family kinases in cancer: from leukaemia to solid tumours. Nat Rev Cancer 13, 559-571 (2013).

97. Reis A, Hermanson O. The DNA glycosylases OGG1 and NEIL3 influence differentiation potential, proliferation, and senescence-associated signs in neural stem cells. Biochem Biophys Res Commun 423, 621-626 (2012).

98. Zhao Z, et al. NEIL3 Prevents Senescence in Hepatocellular Carcinoma by Repairing Oxidative Lesions at Telomeres during Mitosis. Cancer Res 81, 4079-4093 (2021).

99. Meyer C, et al. The MLL recombinome of acute leukemias in 2017. Leukemia 32, 273-284 (2018).

100. Takacova S, et al. DNA damage response and inflammatory signaling limit the MLL-ENL-induced leukemogenesis in vivo. Cancer Cell 21, 517-531 (2012).

101. Tajima K, et al. SETD1A protects from senescence through regulation of the mitotic gene expression program. Nat Commun 10, 2854 (2019).

102. Pfaffl MW. A new mathematical model for relative quantification in real-time RTPCR. Nucleic Acids Res 29, e45 (2001). 
103. Dimri GP, et al. A biomarker that identifies senescent human cells in culture and in aging skin in vivo. Proc Natl Acad Sci U S A 92, 9363-9367 (1995).

104. Kurz DJ, Decary S, Hong Y, Erusalimsky JD. Senescence-associated (beta)galactosidase reflects an increase in lysosomal mass during replicative ageing of human endothelial cells. J Cell Sci 113 ( Pt 20), 3613-3622 (2000).

105. Hydbring P, et al. Phosphorylation by Cdk2 is required for Myc to repress Rasinduced senescence in cotransformation. Proc Natl Acad Sci U S A 107, 58-63 (2010).

106. Dobin A, et al. STAR: ultrafast universal RNA-seq aligner. Bioinformatics 29, 15$21(2013)$.

107. Liao Y, Smyth GK, Shi W. featureCounts: an efficient general purpose program for assigning sequence reads to genomic features. Bioinformatics 30, 923-930 (2014).

108. Love MI, Huber W, Anders S. Moderated estimation of fold change and dispersion for RNA-seq data with DESeq2. Genome Biol 15, 550 (2014).

109. Zhou Y, et al. Metascape provides a biologist-oriented resource for the analysis of systems-level datasets. Nat Commun 10, 1523 (2019).

110. Raudvere $\mathrm{U}$, et al. g:Profiler: a web server for functional enrichment analysis and conversions of gene lists (2019 update). Nucleic Acids Res 47, W191-W198 (2019). 
Tables, Figures and legends

\section{Table 1}

Oligonucleotides

\begin{tabular}{|c|c|c|}
\hline Primer name & Sequence (5'-3') & Function \\
\hline Exon4 Ash2l_for & CCGCTGACACCTTTGGAATA & \multirow{2}{*}{$\begin{array}{l}\text { To Monitor the loss of } \\
\text { exon } 4 \text { of } A s h 2 \text { I from } \\
\text { RNA }\end{array}$} \\
\hline Exon4 Ash2l_rev & TTGCTTCCGGAGAAAGTAGG & \\
\hline P1 & AGGCGCATAACGATACCACGAT & \multirow{2}{*}{$\begin{array}{l}\text { To monitor the loss of } \\
\text { exon } 4 \text { of Ash2l from } \\
\text { genomic DNA }\end{array}$} \\
\hline P2 & CCACAACGGGTTCTTCTGTT & \\
\hline shRNA p19Arf & GAGGGTTTTCTTGGTGAAG & $\begin{array}{l}\text { Insert of retrovirus for } \\
\text { the repression of } p 19 \text { Arf }\end{array}$ \\
\hline \multicolumn{3}{|l|}{ RT-qPCR primers } \\
\hline Mm_Gusb_1_SG & (QT00176715, Qiagen) & Normalizer \\
\hline Mm_Flywch2_1_SG & (QT00160447, Qiagen) & \multirow{11}{*}{$\begin{array}{l}\text { Monitoring of gene } \\
\text { expression }\end{array}$} \\
\hline Mm_Cdh3_1_SG & (QT00108878, Qiagen) & \\
\hline Mm_Tcfl5_1_SG & (QT00153580, Qiagen) & \\
\hline Mm_Cdh17_1_SG & (QT01055110, Qiagen) & \\
\hline Mm_Olfr456_1_SG & (QT00362558, Qiagen) & \\
\hline Mm_Hsp90b1_1_SG & (QT00130522, Qiagen) & \\
\hline Mm_II6_1_SG & (QT00098875, Qiagen) & \\
\hline Mm_II7_1_SG & (QT00101318, Qiagen) & \\
\hline Mm_Ccl2_1_SG & (QT00167832, Qiagen) & \\
\hline Mm_Gstm4_1_SG & (QT00113113, Qiagen) & \\
\hline Mm_Cntln_1_SG & (QT00147189, Qiagen) & \\
\hline
\end{tabular}




\section{Table 2}

Antibodies

\begin{tabular}{|c|c|c|c|c|c|}
\hline \multicolumn{2}{|c|}{\begin{tabular}{|l|l|} 
Antigen & Species \\
\end{tabular}} & Company/Cat no. & \multicolumn{2}{|c|}{ Clonality } & RRID number \\
\hline \multicolumn{6}{|c|}{ Primary antibodies } \\
\hline Actin & Mouse & $\begin{array}{l}\text { MP Biomedicals, } \\
69100, \text { C4 }\end{array}$ & \multicolumn{2}{|c|}{ Monoclonal } & AB_2335304 \\
\hline Ash2I & Rabbit & $\begin{array}{l}\text { Cell Signaling, 5019, } \\
\text { D93F6 }\end{array}$ & \multicolumn{2}{|c|}{ Monoclonal } & AB_1950350 \\
\hline GFP & Goat & $\begin{array}{l}\text { Rockland, 600-101- } \\
215\end{array}$ & \multicolumn{2}{|c|}{ Polyclonal } & AB_218182 \\
\hline H3K4me3 & Rabbit & Abcam, ab8580 & \multicolumn{2}{|c|}{ Polyclonal } & AB_306649 \\
\hline $\mathrm{H} 3 \mathrm{~K} 4 \mathrm{me} 2$ & Rabbit & Abcam, ab7766 & \multicolumn{2}{|c|}{ Polyclonal } & AB_2560996 \\
\hline H3K4me1 & Rabbit & Abcam, ab8895 & \multicolumn{2}{|c|}{ Polyclonal } & AB_306847 \\
\hline H3K9me3 & Rabbit & Abcam, ab8898 & \multicolumn{2}{|c|}{ Polyclonal } & AB_306848 \\
\hline H3K9ac & Rabbit & Abcam, ab4441 & \multicolumn{2}{|c|}{ Polyclonal } & AB_2118292 \\
\hline H3K27me3 & Mouse & Abcam, ab6002 & \multicolumn{2}{|c|}{ Monoclonal } & AB_305237 \\
\hline H3K27ac & Rabbit & Abcam, ab4729 & \multicolumn{2}{|c|}{ Polyclonal } & AB_2118291 \\
\hline H3K79me3 & Rabbit & Abcam, ab2621 & \multicolumn{2}{|c|}{ Polyclonal } & AB_303215 \\
\hline $\mathrm{H} 3$ & Rabbit & Abcam, ab1791 & \multicolumn{2}{|c|}{ Polyclonal } & AB_302613 \\
\hline $\lg G$ & Rabbit & $\begin{array}{l}\text { Diagenode, } \\
\text { C01010080 }\end{array}$ & \multicolumn{2}{|c|}{ Polyclonal } & AB_2722553 \\
\hline Rbbp5 & Rabbit & Bethyl, A300-109A & \multicolumn{2}{|c|}{ Polyclonal } & AB_210551 \\
\hline Wdr5 & Rabbit & Bethyl, A302-429A & \multicolumn{2}{|c|}{ Polyclonal } & AB_1944302 \\
\hline p38MAPK & Rabbit & $\begin{array}{l}\text { Santa Cruz } \\
\text { Biotechnology, sc7149 }\end{array}$ & \multicolumn{2}{|c|}{\begin{tabular}{|l|} 
Polyclonal \\
\end{tabular}} & $\begin{array}{l}\text { Antibody no } \\
\text { longer available }\end{array}$ \\
\hline p38MAPK-P & Rabbit & Cell Signaling, 9211 & Polycl & nal & $A B \_331641$ \\
\hline$\gamma-\mathrm{H} 2 \mathrm{AX}$ & Mouse & $\begin{array}{l}\text { Upstate, Millipore 05- } \\
636\end{array}$ & Monoc & lonal & AB_309864 \\
\hline Secondary a & antibodies & & & & \\
\hline Antigen & Species & Company/Cat no. & & Con & jugation \\
\hline Goat lgG & Mouse & $\begin{array}{l}\text { Santa Cruz Biotechnolo } \\
2354\end{array}$ & gy, sc- & HRP & -conjugated \\
\hline
\end{tabular}




\begin{tabular}{|l|l|l|l|}
\hline Mouse IgG & Goat & $\begin{array}{l}\text { Jackson Immuno Res., 111- } \\
035-146\end{array}$ & HRP-conjugated \\
\hline Rabbit IgG & Goat & $\begin{array}{l}\text { Jackson Immuno Res., 111- } \\
035-144\end{array}$ & HRP-conjugated \\
\hline Rat IgG & Goat & Invitrogen, A-11006 & Alexa Fluor 488 \\
\hline Rat IgG & Goat & Invitrogen, A-21434 & Alexa Fluor 555 \\
\hline Rabbit IgG & Goat & Invitrogen, A-21428 & Alexa Fluor 555 \\
\hline
\end{tabular}




\section{Figures}

A

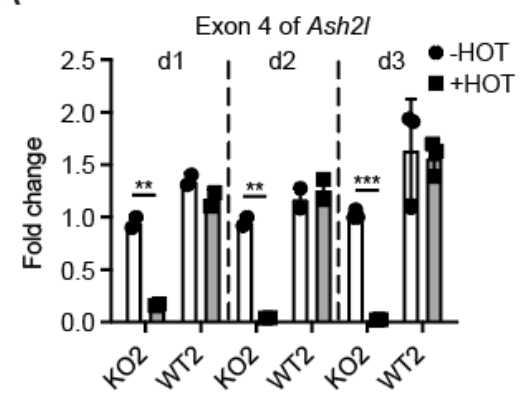

D

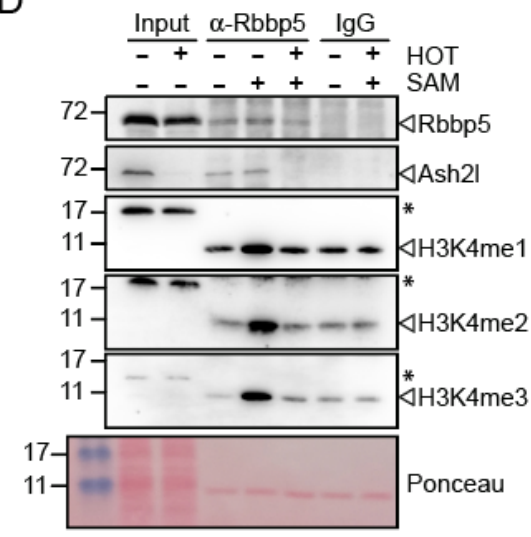

$\mathrm{E}$

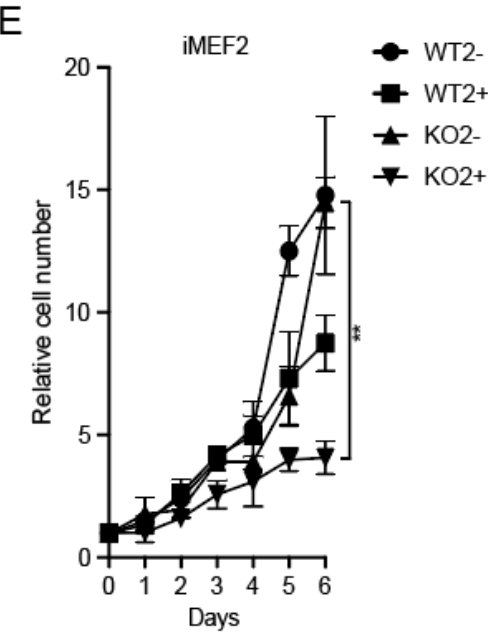

B

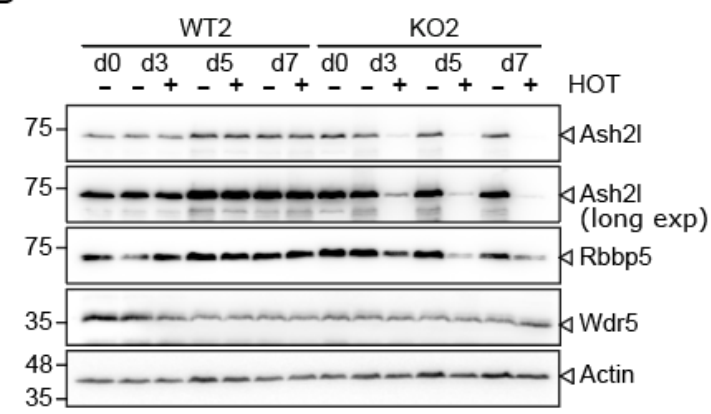

C

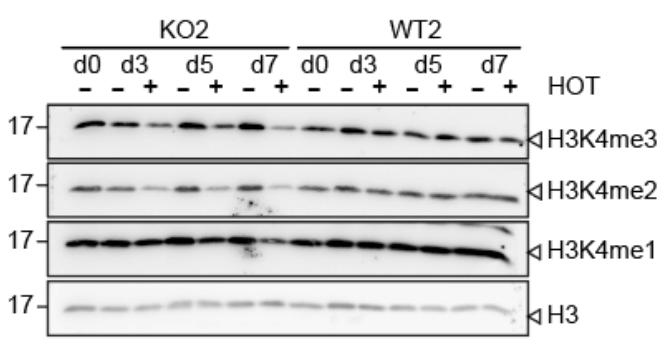

$\mathrm{F}$

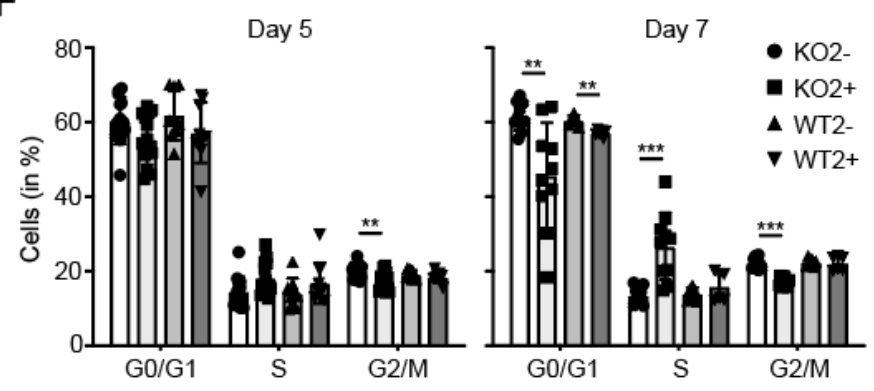

G

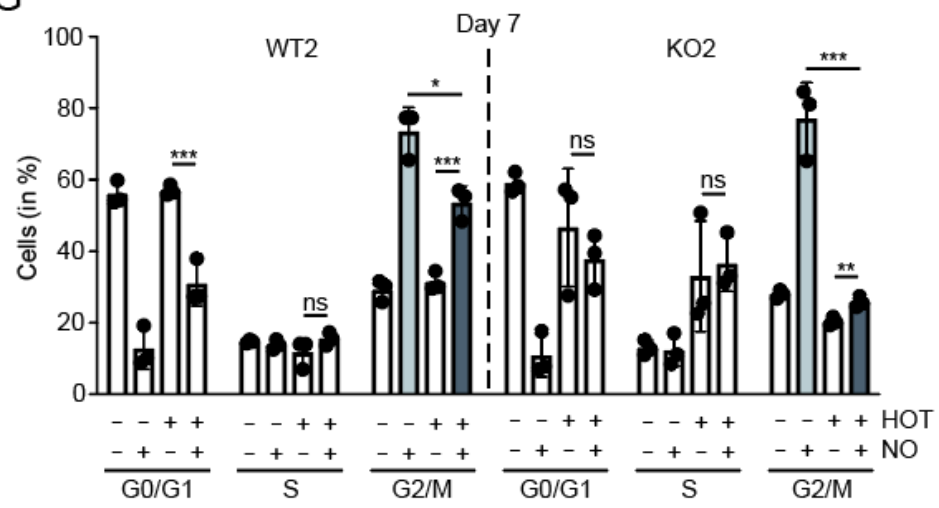

Figure 1

Loss of Ash2l in mouse embryo fibroblasts inhibits proliferation and cell cycle progression.

A. iMEF2 cells (WT2, Ash2/ ${ }^{\text {wt/wt: }}$ Cre-ER ${ }^{T M 2}$; and KO2, Ash2/f//fl: $C r e-E R^{T M 2}$ ) were treated with 4-hydroxy tamoxifen (HOT, $5 \mathrm{nM}$ ) or vehicle as indicated. RT-qPCR analysis of the floxed exon 4 of Ash2l was performed at days 1, 2 and 3. Indicated are mean values $\pm \operatorname{SD}\left({ }^{* * *} p<0.001 ;{ }^{* *} p<0.01\right)$. 
B and C. Wild type (WT1) and Ash2f//fl (KO1) immortalized fibroblasts (iMEF1) were treated \pm HOT for $0,3,5$ or 7 days. The cells were lysed and the indicated proteins analyzed by Western blotting.

D. KO2 cells were treated \pm HOT for 5 days. KMT2 complexes were immunoprecipitated from low stringency lysates using an antibody specific for Rbbp5 or a species matched control antibody (lgG). The immunoprecipitates were incubated in the presence or absence of S-adenosyl-methionine (SAM) and recombinant histone H3. The reactions were analyzed for the proteins indicated using Western blotting. In the input non-specific signals are labeled $\left(^{*}\right)$.

E. Wild type (WT) and $A s h 2 f^{f / f l}(\mathrm{KO})$ immortalized fibroblasts (iMEF2) were treated \pm HOT ( $5 \mathrm{nM}$ ) for the times indicated. The cells were counted daily. Mean values $\pm \mathrm{SD}$ of 4-6 measurements in duplicates for each time point (statistical analyses refer to day $\left.6:{ }^{* *}<0.01\right)$.

F. Cell cycle analysis using flow cytometry of fixed and Hoechst stained WT2 and KO2 cells treated \pm HOT for 5 or 7 days. Mean values \pm SD $\left(n=6-10 ;{ }^{* *}<0.01,{ }^{* * *}<0.001\right)$. G. WT2 and KO2 cells were treated \pm HOT for 7 days. During the last $18 \mathrm{~h}$ the cells were incubated with nocodazole $(100 \mathrm{ng} / \mathrm{ml})$ or vehicle control as indicated. The cells were fixed, the DNA stained using Hoechst and analyzed by flow cytometry. Mean values \pm SD of 3 experiments are shown. Statistical analyses are indicated for selected data sets, ${ }^{*}<0.05,{ }^{* *}<0.01,{ }^{* * *}<0.001$, ns, not significant. 
A

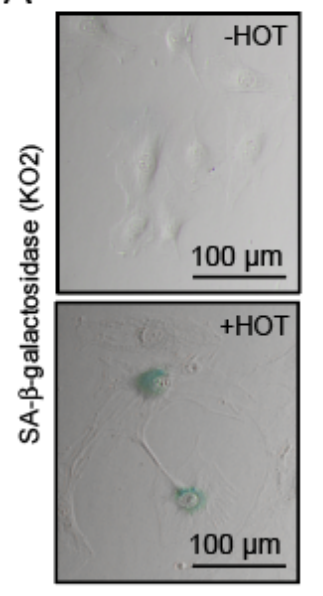

B

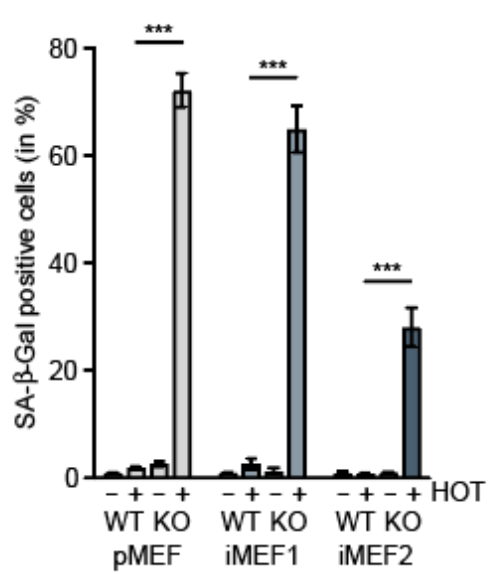

C

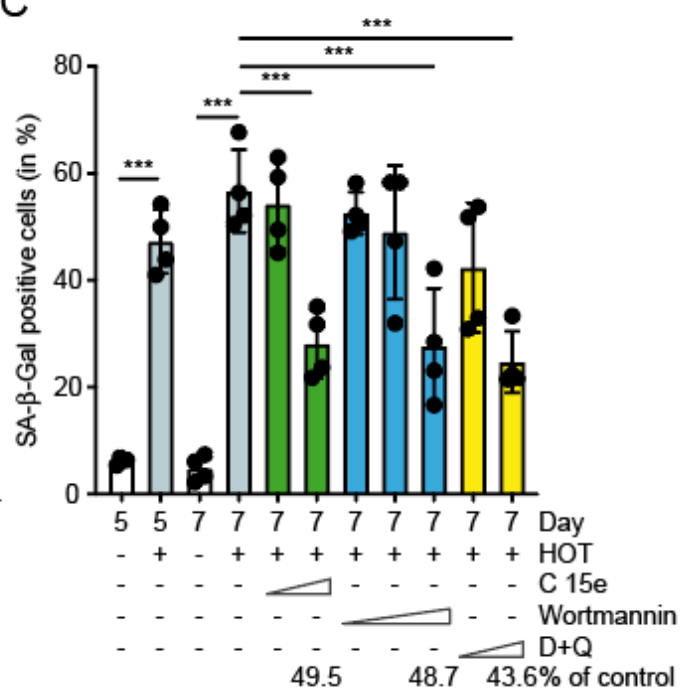

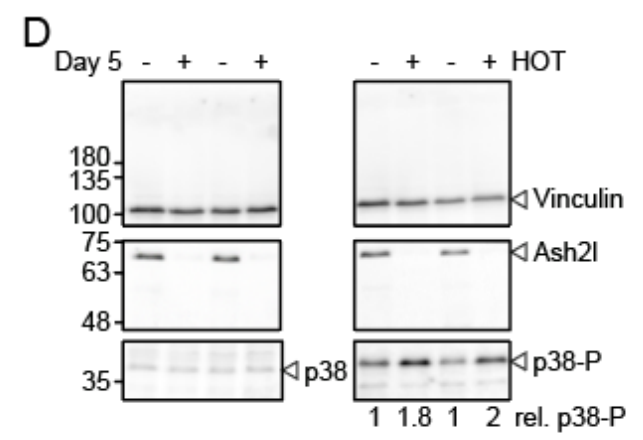

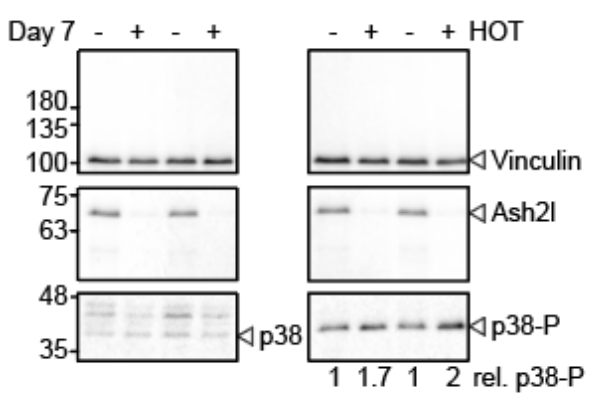

Figure 2

Ash2l loss promotes senescence in MEF cells.

A. KO2 cells were incubated \pm HOT for 7 days. The cells were fixed and stained for SA- $\beta$-galactosidase activity (blue).

B. Primary MEF (pMEF) and iMEF cells were treated \pm HOT for 5 or 7 days as indicated, analyzed as in panel A and the number of SA- $\beta$-gal positive cells determined. Mean values \pm SD of 3-4 experiments are shown. In each experiment 200-300 cells were counted $\left.{ }^{* * *}<0.001\right)$.

C. KO2 cells were incubated \pm HOT for 7 days. During the last 2 days senolytic drugs were added: Compound 15e (1 and $5 \mu \mathrm{M})$, Wortmannin $(0.1,1$ and $10 \mu \mathrm{M})$, and a combination of Dasatinib/Quercetin (25 nM/1.5 $\mu \mathrm{M}$ and $250 \mathrm{nM} / 15 \mu \mathrm{M})$. The percentage of SA- $\beta$-Gal positive cells is displayed. Four sections each with $50-150$ cells of two biological replicates were counted. Mean values $\pm \operatorname{SD}\left(n=4 ;^{* * *}<0.001\right)$. D. KO2 cells were treated \pm HOT for 5 or 7 days (top and bottom panels, respectively). Whole cell lysates of two biological replicates were analyzed by Western blotting using the indicated antibodies. Quantified were p38-P vs. p38 signals. 
A

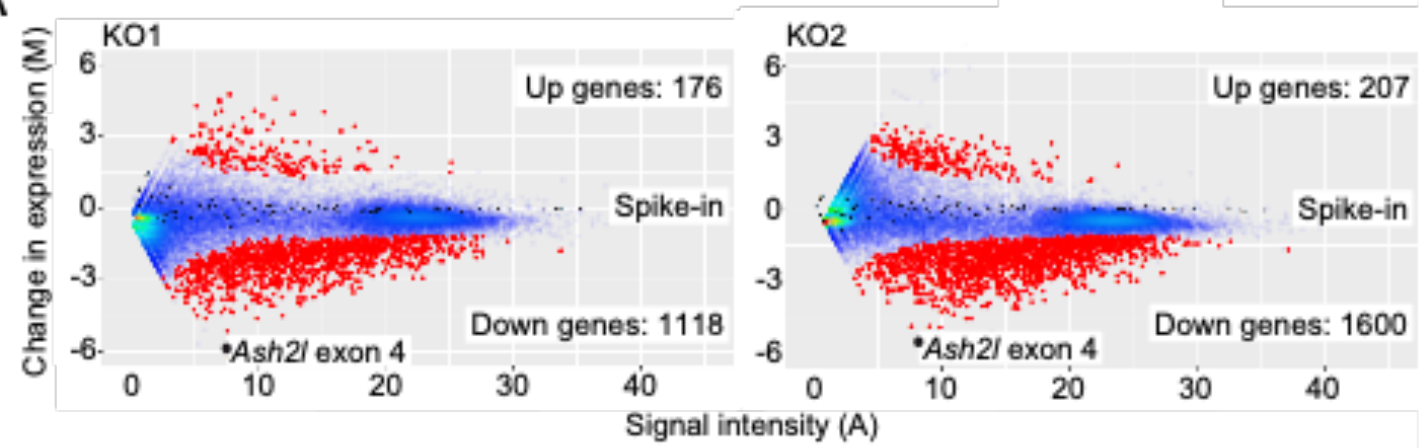

B

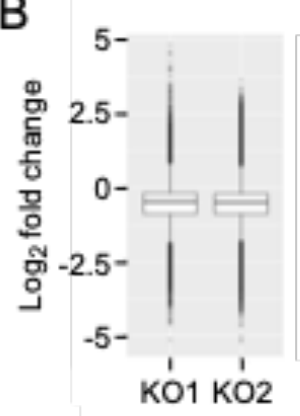

C

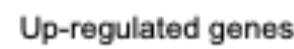
KO1 (176) KO2 (207)

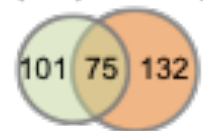

Down-regulated genes

KO1 (1118) KO2 (1600)

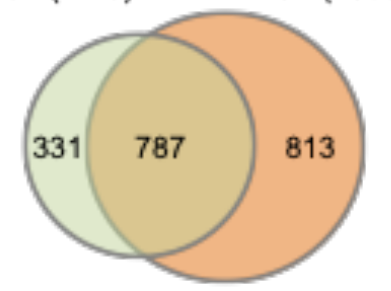

D
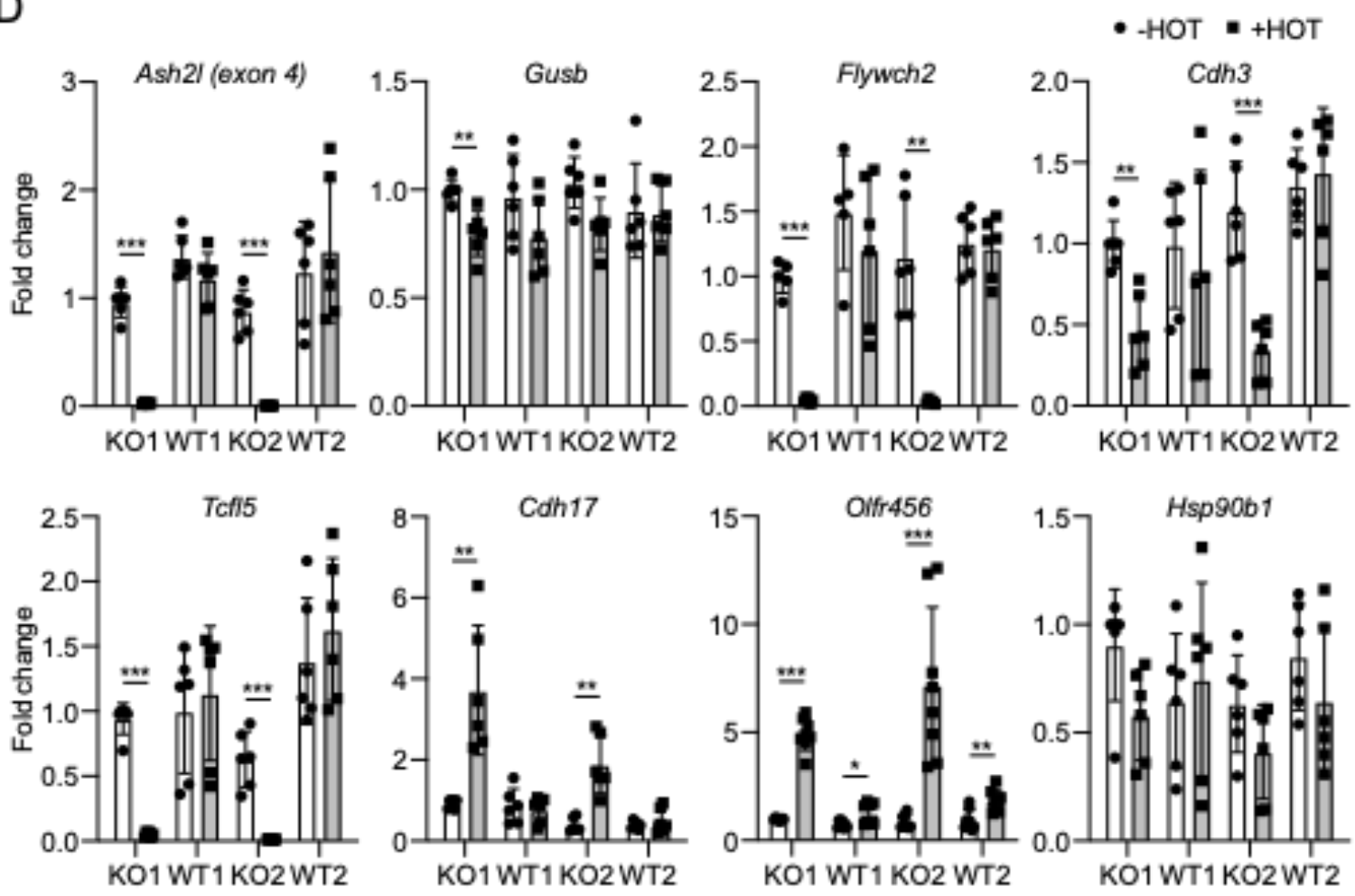

Figure 3

Deregulated gene expression upon loss of Ash2l.

A. $\mathrm{KO} 1$ and $\mathrm{KO} 2$ cells were treated $\pm \mathrm{HOT}$ for 5 days. RNA was isolated and ERCC RNA spike-in control mix added. The RNA was analyzed using next generation sequencing, adjusted to the spike-in RNA. Displayed are MA plots $(\mathrm{A}=$ $\left.0.5\left(\log _{2}(\mathrm{KO}+\mathrm{HOT})+\log _{2}(\mathrm{KO}-\mathrm{HOT})\right) ; \mathrm{M}=\log _{2}(\mathrm{KO}+\mathrm{HOT})-\log _{2}(\mathrm{KO}-\mathrm{HOT})\right)$. The 
number of up- and downregulated genes are indicated ( $p$-value < 0.05). Red dots, significantly regulated genes; blue dots, not regulated genes; black dots, spike-in RNA. The signals obtained for exon 4 of Ash2/ are indicated.

B. Box plot analysis of gene expression in $\mathrm{KO} 1$ and $\mathrm{KO} 2$ cells from the data shown in panel A. A one sample t-test indicates that FC values deviate from 0 ( $p$-value $<2.2 e-$ 16).

C. Comparison of up- and downregulated genes between $\mathrm{KO} 1$ and $\mathrm{KO} 2$ cells.

D. WT and KO iMEF 1 and 2 cells were incubated \pm HOT for 5 days, the RNA isolated and the expression of the indicated genes measured by RT-qPCR. The expression of Gusb was used as reference. Mean values \pm SD $(n=5-8)\left({ }^{*}<0.05,{ }^{* *}<0.01,{ }^{* *}<\right.$ $0.001)$. 
A

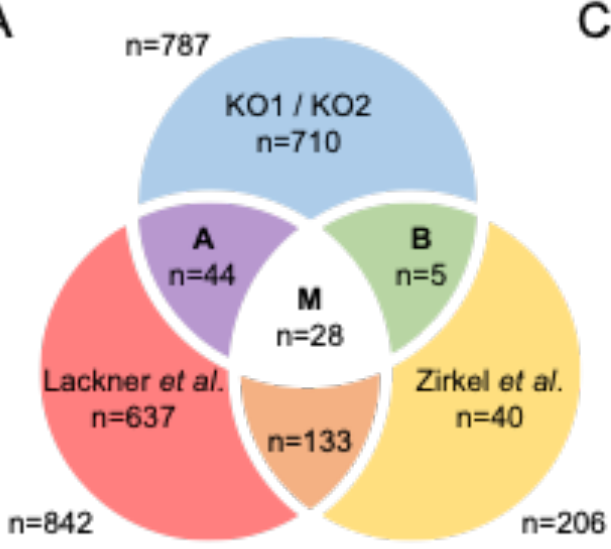

$\mathrm{C}$

Cell cycle

Progesterone-mediated oocyte maturation

Fanconi anemia pathway Cellular senescence

Oocyte meiosis

Human T-cell leukemia virus 1 infection p53 signaling pathway

Human immunodeficiency virus 1 infection

FoxO signaling pathway
AM BM M

$2.78 \quad 6.34 \quad 3.79$

$\begin{array}{llll}3.20 & 4.07 & 2.92\end{array}$

ns $1.85 \quad 2.20$

ns $4.16 \quad 2.34$

ns 3.712 .73

ns $2.65 \quad 2.11$

ns 2.912 .04

ns ns 1.66

ns 1.62 ns

$-\log _{10}(\mathrm{P})$

\section{B}

\begin{tabular}{lll} 
& \multicolumn{2}{c}{ Expression } \\
\cline { 3 - 3 } 을 & Kene & KO1 KO2 \\
B Neurl1b & \\
A Ralgps2 & \\
A As3mt \\
A Lin7a \\
A Enpp2 \\
A Matn3 \\
A Pde3b \\
M Fam64a \\
A Selenbp1 \\
A Gcnt1 \\
A Phf19 \\
A Kctd14 \\
M Mnd1 \\
A Gng2 \\
A Cenpv \\
A Col14a1 \\
A Cd302 \\
A Frzb \\
B Emp2 \\
A Hnmt
\end{tabular}

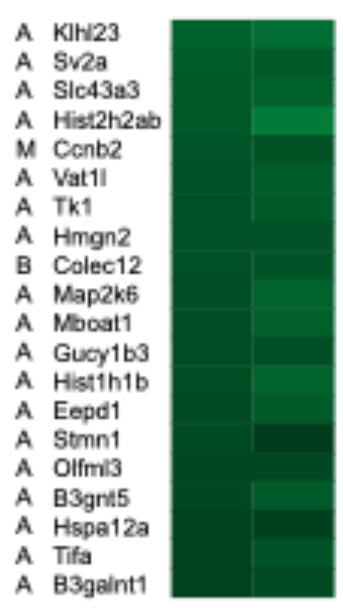

\section{A Galm}

M Melk

M Hmgb2

A Fam129a

B E212

M Fignl1

M Top2a

A Coca 7

M K $\mathrm{K} / 23$

M Pbk

M Shcbp1

M Cenpa

A Rtkn2

M Neil3

M Colon3

M Digap6

M Fancb

M Kif15

A Cde25b

M Ska1

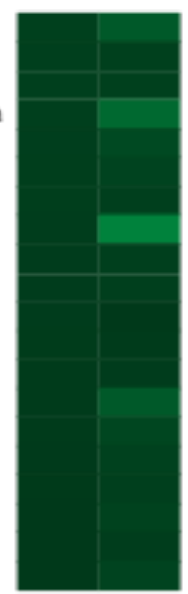

Figure 4

A. Commonly downregulated genes in murine $\mathrm{KO} 1$ and $\mathrm{KO} 2$ cells upon loss of Ash2l were compared to commonly downregulated genes in 3 primary human cell populations ${ }^{35}$ and to downregulated genes in human diploid fibroblasts ${ }^{34}$ in response to replicative senescence. The number of genes is indicated that are in common between the different groups: $\mathrm{A}, \mathrm{KO} 1 / \mathrm{KO} 2$ and the genes in Lackner et al.; $\mathrm{B}, \mathrm{KO} 1 / \mathrm{KO} 2$ and the genes in Zirkel et al.; $\mathrm{M}$, common genes of all three studies. Comparison KO1/KO2 with Lackner et al. and Zirkel et al.: p-value < 2.2e-16 (Fischer Exact test). $B$. The genes in groups $A, B$ and $M$ are listed and the repression of these genes in both $\mathrm{KO} 1$ and $\mathrm{KO} 2$ cells upon treatment \pm HOT for 5 days is indicated.

C. GO pathway analysis of the genes that are in common between the data sets of panel D. Adjusted p-values are indicated; ns, not significant. 
A

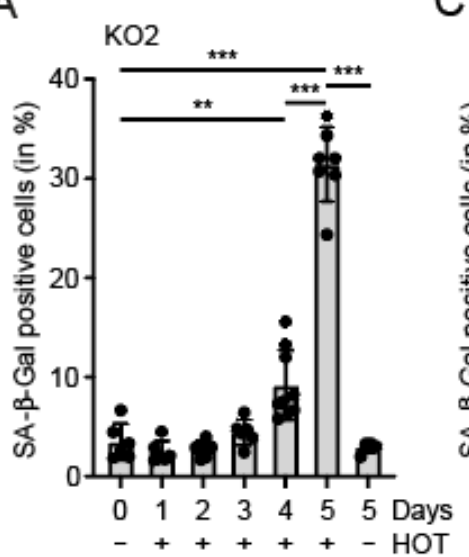

B
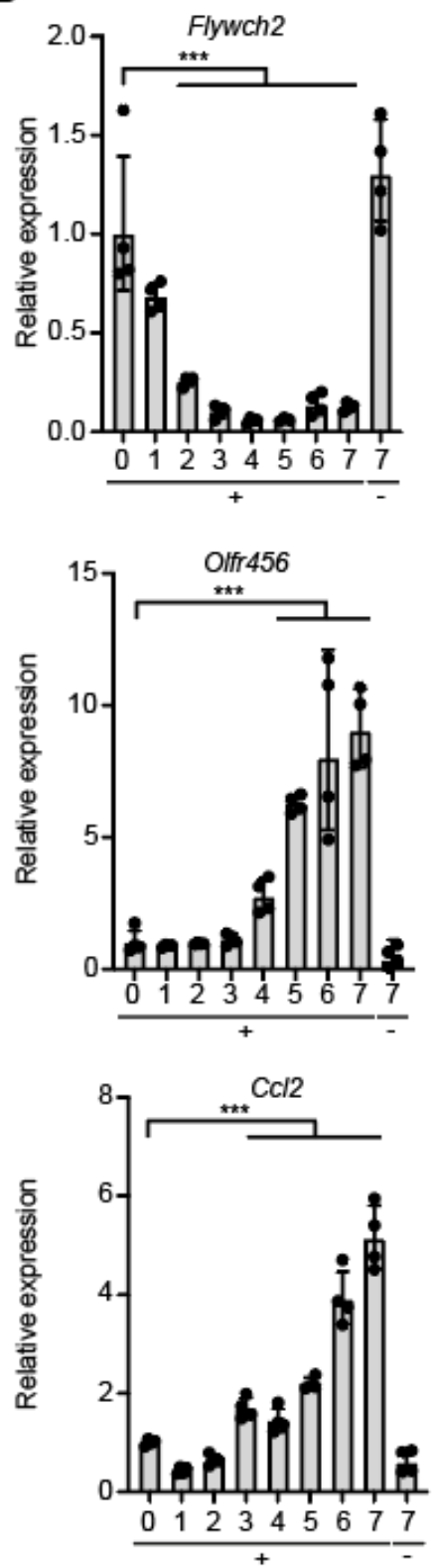

C

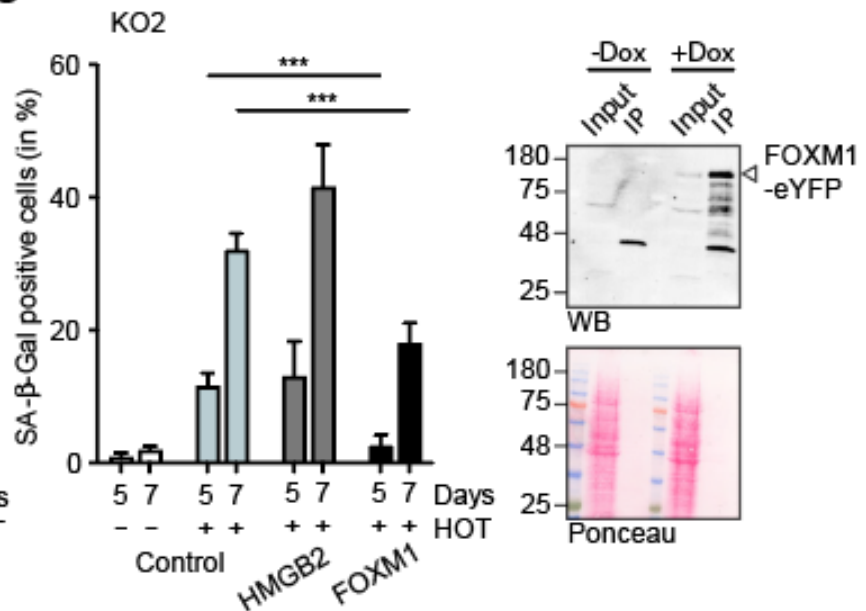

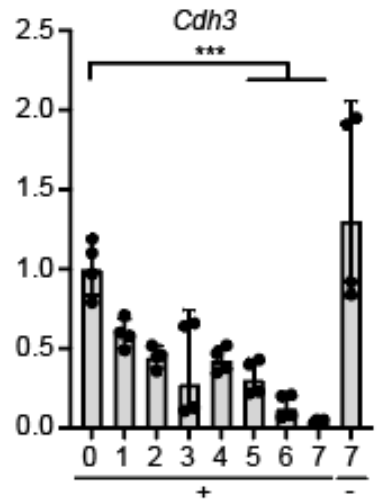
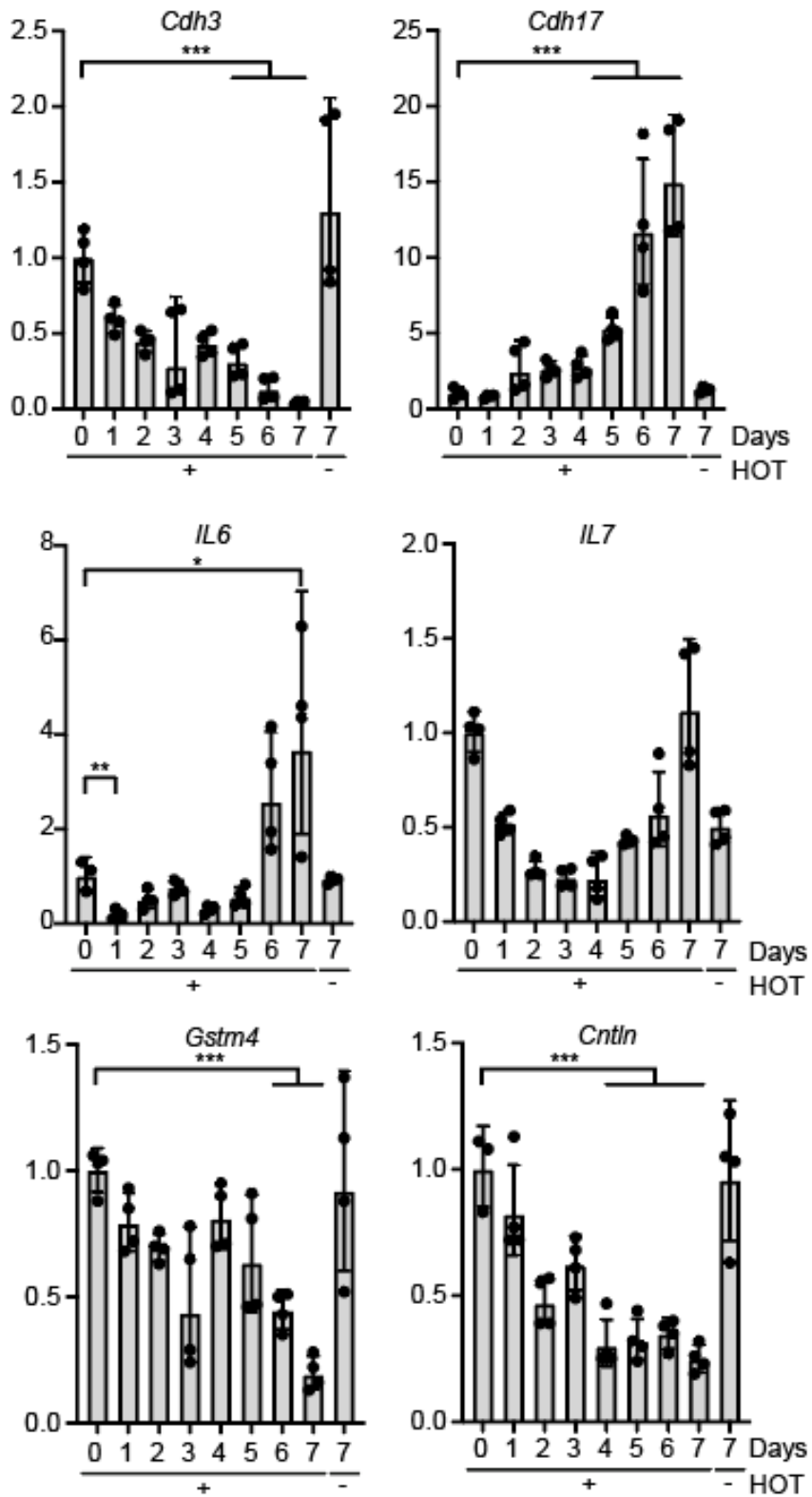

Figure 5

FOXM1 delays Ash2I loss induced senescence. 
A. KO2 cells were treated with \pm HOT for the indicated days. Then cells were fixed and stained for SA- $\beta$-galactosidase activity and counted. Mean values \pm SD $(n=6-7)(p=$ $\left.{ }^{*}<0.05,{ }^{* *}<0.01,{ }^{* * *}<0.001\right)$.

B. KO2 cells were incubated \pm HOT for 1-7 days, the RNA isolated and the expression of the indicated genes measured by RT-qPCR. The expression of Gusb was used as control. Mean values $\pm \operatorname{SD}(n=4)\left({ }^{*}<0.05,{ }^{* *}<0.01,{ }^{* * *}<0.001\right)$.

C. KO2 cells were infected with lentiviruses expressing HMGB2 and FOXM1 (as eYFP fusion proteins). Pools of cells were treated with HOT as indicated and with doxycycline (Dox). The number of SA- $\beta$-galactosidase positive cells was determined at days 5 and 7. Slides of two biological replicates analyzed in duplicates were blinded and counted by 3 persons. The resulting mean values \pm SD $\left({ }^{* *}<0.001\right)$ are depicted. The panel on the right documents FOXM1-eYFP expression in KO2 cells upon induction with Dox using Western blotting (WB). Input refers to $2.5 \%$ of total cell lysate, the remainder was used for immunoprecipitating the fusion protein (IP). Prior to specific protein detection, the membranes were stained with Ponceau $S$ to verify equal loading of input lysates. 